\title{
Summary of Data from the Fifth AIAA CFD Drag Prediction Workshop
}

\author{
David W. Levy ${ }^{1}$ and Kelly R. Laflin ${ }^{2}$ \\ Cessna Aircraft Company, Wichita, KS 67215, USA \\ Edward N. Tinoco ${ }^{3}$, John C. Vassberg ${ }^{4}$, Mori Mani ${ }^{5}$, and Ben Rider ${ }^{6}$ \\ The Boeing Company, Seattle, WA, 98124, Huntington Beach, CA 92647, St. Louis, MO, 63301, USA \\ Chris Rumsey $^{7}$, Richard A. Wahls ${ }^{8}$ and Joseph H. Morrison ${ }^{9}$ \\ NASA Langley Research Center, Hampton, VA 23681, USA \\ Olaf P. Brodersen ${ }^{10}$ and Simone Crippa ${ }^{10}$ \\ DLR Institute of Aerodynamics and Flow Technology, 38108 Braunschweig, Germany \\ Dimitri J. Mavriplis ${ }^{11}$ \\ University of Wyoming, Laramie, WY 82071, USA \\ and \\ Mitsuhiro Murayama ${ }^{10}$ \\ Japan Aerospace Exploration Agency, Chofu, Tokyo 182-8522, Japan
}

\begin{abstract}
Results from the Fifth AIAA CFD Drag Prediction Workshop (DPW-V) are presented. As with past workshops, numerical calculations are performed using industry-relevant geometry, methodology, and test cases. This workshop focused on force/moment predictions for the NASA Common Research Model wing-body configuration, including a grid refinement study and an optional buffet study. The grid refinement study used a common grid sequence derived from a multiblock topology structured grid. Six levels of refinement were created resulting in grids ranging from $0.64 \times 10^{6}$ to $138 \times 10^{6}$ hexahedra - a much larger range than is typically seen. The grids were then transformed into structured overset and hexahedral, prismatic, tetrahedral, and hybrid unstructured formats all using the same basic cloud of points. This unique collection of grids was designed to isolate the effects of grid type and solution algorithm by using identical point distributions. This study showed reduced scatter and standard deviation from previous workshops. The second test case studied buffet onset at $M=0.85$ using the Medium grid $\left(5.1 \times 10^{6}\right.$ nodes $)$ from the above described sequence. The prescribed alpha sweep used finely spaced intervals through the zone where wing separation was expected to begin. Some solutions exhibited a large side of body separation bubble that was not observed in the wind tunnel results. An optional third case used three sets of geometry, grids, and conditions from the Turbulence Model Resource website prepared by the Turbulence Model Benchmarking Working Group. These simple cases were intended to help identify potential differences in turbulence model implementation. Although a few outliers and issues affecting consistency were identified, the majority of participants produced consistent results.
\end{abstract}

\footnotetext{
${ }^{1}$ Principal Engineer, AIAA Associate Fellow

${ }^{2}$ Engineer Specialist, Sr., AIAA Associate Fellow

${ }^{3}$ Boeing Technical Fellow (Retired), AIAA Associate Fellow

${ }^{4}$ Boeing Technical Fellow, AIAA Fellow

${ }^{5}$ Boeing Sr. Technical Fellow, AIAA Associate Fellow

${ }^{6} \mathrm{Sr}$. Engineer, AIAA Member

${ }^{7}$ Senior Research Scientist, AIAA Fellow

${ }^{8}$ Assistant Head, Configuration Aerodynamics Branch, AIAA Associate Fellow

${ }^{9}$ Head, Computational AeroSciences Branch, AIAA Associate Fellow

${ }^{10}$ Research Engineer, AIAA Member

${ }^{11}$ Professor Mechanical Engineering, AIAA Associate Fellow
} 


$\begin{array}{ll}\text { AR } & \text { Wing Aspect Ratio } \\ b & \text { Wing Span } \\ \text { BL } & \text { Butt Line Coordinate } \\ C_{D} & \text { Drag Coefficient }\left(C_{-} \text {TOT }\right) \\ C_{D P} & \text { Idealized Profile Drag }=\mathrm{C}_{\mathrm{D}}-\mathrm{C}_{\mathrm{L}}{ }^{2} / \pi \mathrm{AR} \\ \mathrm{C}_{\mathrm{Dpr}} & \text { Pressure Drag Coefficient }\left(\mathrm{CD} \_\mathrm{PR}\right) \\ \mathrm{C}_{\mathrm{Dsf}} & \text { Skin-Friction Drag Coefficient }\left(\mathrm{CD} \_\mathrm{SF}\right) \\ \mathrm{C}_{\mathrm{L}} & \text { Lift Coefficient } \\ \mathrm{C}_{\mathrm{M}} & \text { Pitching Moment Coefficient }(\mathrm{CM} \text { _TOT) } \\ \mathrm{C}_{\mathrm{P}} & \text { Pressure Coefficient }=\left(\mathrm{P}-\mathrm{P}_{\infty}\right) / \mathrm{q}_{\infty} \\ \mathrm{C}_{\mathrm{ref}} & \text { Wing Reference Chord } \sim \text { MAC } \\ \mathrm{C}_{\mathrm{f}} & \text { Local Coefficient of Skin Friction } \\ \mathrm{FS} & \text { Fuselage Station Coordinate }\end{array}$

\section{Nomenclature}

$\begin{array}{ll}\text { LE } & \text { Wing Leading Edge } \\ \text { MAC } & \text { Mean Aerodynamic Chord } \\ \text { N } & \text { Number of unknowns (GRIDSIZE) } \\ \text { RANS } & \text { Reynolds-Averaged Navier-Stokes } \\ \text { RE } & \text { Reynolds Number } \\ \text { Sef }_{\text {ref }} & \text { Reference Area } \\ \text { SOB } & \text { Side-of-Body } \\ \text { TE } & \text { Wing Trailing Edge } \\ \text { WL } & \text { Water Line Coordinate } \\ y^{+} & \text {Normalized Wall Distance } \\ \alpha & \text { Angle of Attack (ALPHA) } \\ \eta & \text { Fraction of Wing Semi-Span }\end{array}$

\section{Introduction}

The AIAA CFD Drag Prediction Workshop (DPW) Series was initiated by a working group of members from the Applied Aerodynamics Technical Committee of the American Institute of Aeronautics and Astronautics. The primary goal of the workshop series is to assess the state-of-the-art of modern computational fluid dynamics methods using geometries and conditions relevant to commercial aircraft. From the onset, the DPW organizing committee has adhered to a primary set of guidelines and objectives for the DPW series:

- Assess state-of-the-art Computational Fluid Dynamics (CFD) methods as practical aerodynamic tools for the prediction of forces and moments on industry-relevant geometries, with a focus on absolute drag.

- Provide an impartial international forum for evaluating the effectiveness of CFD Navier-Stokes solvers.

- Promote balanced participation across academia, government labs, and industry.

- Use common public-domain subject geometries, simple enough to permit high-fidelity computations.

- Provide baseline grids to encourage participation and help reduce variability of CFD results.

- Openly discuss and identify areas needing additional research and development.

- Conduct rigorous statistical analyses of CFD results to establish confidence levels in predictions.

- Schedule open-forum sessions to further engage interaction among all interested parties.

- Maintain a public-domain accessible database of geometries, grids, and results.

- Document workshop findings; disseminate this information through publications and presentations.

Four previous workshops have been held prior to the present study, all held in conjunction with the AIAA Applied Aerodynamics Conference for that year:

\begin{tabular}{|l|l|l|l|}
\hline Year & Location & Configuration & Case Descriptions \\
\hline 2001 & Anaheim, CA & DLR-F4 Wing-Body & $\begin{array}{l}\text { Single Point Grid Refinement Study } \\
\text { Drag Polar } \\
\text { Drag Rise Curves at Constant } \mathrm{C}_{\mathrm{L}}{ }^{*}\end{array}$ \\
\hline 2003 & Orlando, FL & $\begin{array}{l}\text { DLR-F6 Wing-Body } \\
\text { Wing-Body-Nacelle }\end{array}$ & $\begin{array}{l}\text { Single Point Grid Refinement Study } \\
\text { Drag Polar } \\
\text { Boundary Layer Trip Study } \\
\text { Drag Rise Curves at Constant } \mathrm{C}_{\mathrm{L}}^{*}\end{array}$ \\
\hline 2006 & San Francisco, CA & $\begin{array}{l}\text { DLR-F6 Wing-Body with } \\
\text { and without FX2B fairing; } \\
\text { W1/W2 Wing Alone }\end{array}$ & $\begin{array}{l}\text { Single Point Grid Refinement Study } \\
\text { Drag Polar } \\
\text { Grid Convergence Study } \\
\text { Drag Polar }\end{array}$ \\
\hline 2009 & San Antonio, TX & $\begin{array}{l}\text { Common Research Model } \\
\text { Wing-Body and Wing-Body-Tail }\end{array}$ & $\begin{array}{l}\text { Grid Convergence Study } \\
\text { Downwash Study } \\
\text { Mach Sweep Study* } \\
\text { Reynolds Number Study* }\end{array}$ \\
\hline
\end{tabular}


While there have been some variations, the workshops have typically used subjects based on commercial transport wing-body configurations - a consensus of the organizing committee based on a reasonable compromise between simplicity and industry relevance. The vast majority of the participants submit results generated with Reynolds Averaged Navier-Stokes (RANS) codes, although the organizing committee does not restrict the methodology.

The first Drag Prediction Workshop ${ }^{1}$ used the DLR-F4 geometry for the above reasons and due to the availability of publically released geometry and wind tunnel results ${ }^{2}$. The focus of the workshop was to compare absolute drag predictions, including the variation due to grid type and turbulence model type. The results were also compared directly to the available wind tunnel data. The workshop committee provided a standard set of multiblock structured, overset, and unstructured grids for the DLR-F4 geometry to encourage participation in the workshop and reduce variability in the CFD results. However, participants were also encouraged to construct their own grids using their best practices so that learned knowledge concerning grid generation and drag prediction might be shared among workshop attendees. The test cases were chosen to reflect the interests of industry and included a fixed- $\mathrm{C}_{\mathrm{L}}$ single point solution, drag polar, and constant- $\mathrm{C}_{\mathrm{L}}$ drag rise data sets. To help encourage wide participation, a formal paper documenting results was not required at the workshop. Eighteen participants submitted results, using 14 different CFD codes; many submitted multiple sets of data exercising different options in their codes, e.g., turbulence models and/or different grids. A summary of these results was documented by the DPW-I organizing committee $^{3}$. Because of strong participation, DPW-I successfully amassed a CFD data set suitable for statistical analysis ${ }^{4}$. However, the results of that analysis were rather disappointing, showing a 270 -drag-count spread in the fixed- $\mathrm{C}_{\mathrm{L}}$ data, with a 100:1 confidence interval of more than \pm 50 drag counts.

Despite the somewhat disappointing results, the consensus of the participants and organizers was that DPW-I was a definitive success. First and foremost it was initiated as a "grass roots" effort by CFD developers, researchers, and practitioners to focus on a common problem of interest to the aerospace industry. There was open and honest exchange of common practices and issues which identified areas for further research and scrutiny. The workshop framework was tested successfully on high fidelity 3D RANS methods using a common geometry, grids, and test cases. Finally, it reminded the CFD community that CFD is not a fully mature discipline.

The interest generated from the workshop was continued and resulted in several individual efforts documenting results more formally ${ }^{5-8}$, presented at a special session of the 2002 AIAA Aerospace Sciences Meeting and Exhibit in Reno, NV. The interest generated by DPW-I naturally led to the planning and organization of the 2nd AIAA Drag Prediction Workshop, DPW-II. The DPW-II organizing committee, recognizing the success of DPW-I, maintained the format and objectives for DPW-II.

The second workshop 9 used the DLR-F6 as the subject geometry in both wing-body (WB, similar to DLF-F4) and wing-body-nacelle-pylon (WBNP) form. The DPW-II organizing committee worked with DLR and ONERA to make pertinent experimental data available to the public domain. One specific objective of DPW-II was the prediction of the incremental drag associated with nacelle/pylon installation. The F6 geometry contained pockets of flow separation more severe than the F4; occurring predominantly at the wing/body and wing/pylon juncture regions. The results from the workshop were documented with a summary paper, ${ }^{10}$ a statistical analysis, ${ }^{11}$ an invited reflections paper $^{12}$ on the workshop series, and numerous participant papers ${ }^{13-21}$ in two special sessions of the 2004 AIAA Aerospace Sciences Meeting in Reno, NV. A conclusion of DPW-II was that the separated flow regions made it difficult to draw meaningful conclusions with respect to grid convergence and drag prediction. During the follow-up open-forum discussions, the CFD community voiced the desire for the organizing committee to include in the third workshop: a) Blind Test Cases, and b) Simpler Geometries. The request for blind test cases is motivated by an earnest attempt to better establish a measure of the CFD community's capability to predict absolute drag, rather than match it after-the-fact. The request for simpler geometries allows more extensive research in studies of asymptotic grid convergence.

The third workshop ${ }^{22}$ retained the DLR-F6 WB from DPW-II as a baseline configuration to provide a bridge to the previous workshop. However, to test the hypothesis that the grid-convergence issues of DPW-II were the direct result of the large pockets of flow separation, a new wing-body fairing was designed to eliminate the side-of-body separation. Details of the FX2B fairing design are documented by Vassberg ${ }^{23}$. In addition, to help reduce the wing upper-surface trailing-edge flow separation, a higher Reynolds number was introduced for the WB test cases. These changes in both geometry and flow condition also provided the DPW-III participants a blind test since no test data would be available prior to the workshop. Furthermore, two wing-alone geometries were created to provide workshop participants with simpler configurations on which more extensive grid-convergence studies could be conducted; these wings were designed to exhibit no appreciable separation at their design conditions. The DPW-III was heavily documented with summary papers ${ }^{24,25}$, a statistical analysis $\operatorname{paper}^{26}$, participant papers ${ }^{27-30}$, and a special section of the AIAA Journal of Aircraft, edited by Vassberg ${ }^{31-36}$. After three workshops, the organizing committee 
recognized that a recurring theme of the workshop series was related to grid quality and resolution - see Mavriplis et al. ${ }^{37}$.

For the fourth workshop ${ }^{38}$ a completely new geometry was developed, called the Common Research Model (CRM). The CRM was developed by NASA's Subsonic Fixed Wing (SFW) Aerodynamics Technical Working Group (TWG), in collaboration with the DPW Organizing Committee. This wing-body-horizontal (with and without nacelle-pylons) configuration is representative of a contemporary high-performance transonic transport. A detailed description of its development is given by Vassberg et al. ${ }^{39}$.

One aspect of DPW-IV different from the first three workshops was in the timing of the availability of windtunnel test data on the subject geometries. In DPW-IV, the workshop was held before any experimental data were collected and is a set of blind tests. Another advantageous outcome of this collaborative endeavor is that the CRM has been tested in two facilities thus far, and the data from these tests is publicly available. The National Transonic Facility (NTF) at NASA Langley tested the CRM during Jan-Feb 2010, and then it was evaluated at the Ames 11-ft wind-tunnel during Mar-Apr 2010. Data from the NTF and Ames tests have been released to the public domain by Rivers and Dittberner ${ }^{40-42}$.

Due to past observations of grid dependence on the solutions, a greater emphasis was placed on establishing meshing guidelines for the generation of baseline grid families. With these guidelines in place, grids were requested from several organizations for structured multiblock, overset, and unstructured types. Each grid family was required to include a Coarse (C), Medium (M), and Fine (F) grid; adding an optional Extra-Fine (X) grid was also encouraged. Target sizes for these grids were 3.5, 10, 35, and 100 million unknowns, respectively. The Medium mesh was intended to be representative of current engineering applications of CFD being used to estimate absolute drag levels on similar configurations. A total of 74 meshes of 18 families were provided and made available to participants for use.

The fourth workshop requested grid convergence and Mach sweep computations as in the previous workshops, plus downwash and Reynolds Number studies. Data were submitted from 19 organizations totaling 29 individual datasets. For the grid refinement study, a Richardson Extrapolation methodology was employed to estimate a continuum value for the total drag coefficient. The range for the total drag coefficient spanned 152 counts, which is a definite improvement over DPW-I. (Excluding a single outlier, the scatter band reduces dramatically to 41 counts.) While this improvement is quite significant, the confidence level is not down to a low enough level to compete with experimental methods. Documentation for these results can be found in summary papers ${ }^{43-44}$ and in individual contributing papers ${ }^{45-58}$ from two special sessions held at the $28^{\text {th }}$ Applied Aerodynamics Conference in June 2010.

Despite the emphasis placed on grid generation with the intent of reducing the associated errors, the variation in the results was still disappointing. For the fifth workshop ${ }^{59}$, a new approach was taken with the intent of reducing grid-related errors even further. As with the fourth workshop, the NASA Common Research Model wing body configuration was used for the geometry. For the grids, a unified baseline ${ }^{60}$ family of Multiblock Structured meshes were developed with six different levels ranging in size from $136 \times 10^{6}$ (Superfine) to $0.64 \times 10^{6}$ (Tiny). Each successive coarse level was derived directly from the finest mesh. Only five blocks were used. Once the cloud of points was defined for this series of grids, then Overset and Unstructured grids were derived. The unstructured grids were defined in Hexahedral, and Prismatic elements, plus a hybrid grid with Prismatic boundary layer and Tetrahedral field elements was defined.

The test cases included a grid refinement study using the common grids or user-supplied custom grids if desired. The second case focused on buffet prediction, with a finely spaced alpha sweep spanning the range where flow separation on the wing was observed in the wind tunnel data and the results in DPW-IV. This is a change from previous workshops, where angle-of-attack sweeps from 0 to $4^{\circ}$ were calculated for the purpose of determining trimmed drag polars. The high-speed lines development is less than $25 \%$ of the total Aerodynamics related airplane development effort. Significant effort must also be paid to Loads and Stability and Control concerns. Many of these high-speed flight concerns occur at the edges of the flight envelope, which are characterized by large regions of separated flows. For the Fifth Drag Prediction Workshop the buffet study has been included to assess CFD prediction in this regime. The optional third test case used geometries, grids, and conditions from the Turbulence Model Resource website ${ }^{61}$ prepared by the Turbulence Model Benchmarking Working Group. Three cases were selected: 1) 2D Zero Pressure Gradient Flat Plate, 2) 2D Bump-in-channel, and 3) 2D NACA 0012 Airfoil. These test cases were designed to discriminate between turbulence model implementations through rigorous grid convergence studies.

This paper presents an overview of the geometry and grid definitions used for the fifth Drag Prediction Workshop. The participant data for the Case 1 grid refinement study are analyzed, including Force/Moment predictions, wing pressure distributions, and flow separation at the wing/body trailing edge juncture. A Richardson 
Extrapolation is performed to estimate the continuum force levels. Comparisons are made to force, moment, and pressure data from the NTF and Ames wind tunnel tests. Analysis of the Case 2 buffet study is presented, including force/moment and pressure predictions with comparisons to wind tunnel data. Flow separation predictions at the wing/body trailing edge juncture and wing trailing edge are shown. Detailed grid convergence studies for drag and skin friction coefficient for the Case 3 Turbulence Modeling results are also discussed.

\section{Geometry Description}

The subject geometry for DPW-V Cases 1 and 2 is the Common Research Model ${ }^{39}$ (CRM) developed jointly by NASA's Subsonic Fixed Wing (SFW) Aerodynamics Technical Working Group (TWG) and the DPW Organizing Committee. The CRM is representative of a modern transonic commercial transport airplane, and was designed in the full configuration with a low wing, body, horizontal tail, and engine nacelles mounted below the wing. For this workshop, only the wing-body configuration was used. A rendering of the geometry is shown in Figure 1, along with a photo of the wind tunnel model installed in the NASA Ames 11ft Transonic Wind Tunnel (with horizontal tail). The CRM was also the subject geometry for DPW-IV.

The wing was designed for a nominal conditions of Mach $=0.85, \mathrm{C}_{\mathrm{L}}=0.50$, and Reynolds Number $40 \times 10^{6}$ based on $\mathrm{c}_{\text {ref. }}$. Pertinent geometric parameters are listed in Table 1. The wing is a supercritical design, and the Boeing Company took the lead on the aerodynamic design. Certain features were designed in to the wing profile for the purposes of research and development. The upper-surface pressure recovery over the outboard wing is intentionally made aggressively adverse over the last $10-15 \%$ local chord to promote separation of the upper-surface boundary layer in close proximity to the wing trailing edge (TE) at lift conditions slightly above the design point. The strong adverse pressure gradient will likely amplify the differences in various turbulence models that may be employed by DPW participants. The span loading was designed to be very nearly elliptical as compared to a more practical design which will find a compromise distribution due to structural constraints. This feature is included to provide a challenge for possible future workshops on aerodynamic shape optimization.

\section{Gridding Guidelines and Description of Common Grids}

As mentioned above, a common theme and discussion topic in the DPW series is the effect of the computational grid on the results. A substantial effort was made in DPW-IV to address this, yet there was still significant variation in the results among the different grid types. The Organizing Committee recognized that a relatively simple Multiblock Structured (MB) grid could be created for the CRM wing-body geometry that conformed to the desired gridding guidelines. These gridding guidelines have been developed over the course of the DPW series and are listed in Table 2. The grid topology for the MB grid is shown in Figure 2.

The finest grid (L6) was generated first and is sized to extend well into the asymptotic range of grid convergence, while the coarsest grid (L1) would still be "multigrid friendly" for up to 3 levels. The next coarser level (L5) was obtained by replacing every three cells in each of the I, J, \& K directions with two cells. The L4 grid was created from L6 by removing every other point in each of the (I, J, \& K) directions, and L3 by doing the same starting from the L5 grid. The process is repeated with the L4 and L3 grids to complete the sequence at L2 and L1. By interleaving the even and odd levels a complete family of six grids is constructed. See Vassberg ${ }^{60}$ for detailed information.

Once the MB series was developed, then a set of unified grids for other types were derived. The Overset series was created by extending each block using data from neighboring blocks to define four patch grids to bridge each block. The patch grids overlap each block by three cells as shown in Figure 3, and are point matched to minimize interpolation errors. One issue was found on the $\mathrm{K}=1$ plane for the mid-body block, where the $\mathrm{J}$ line had mixed symmetry plane and block boundary conditions. This issue caused difficulty for some participants.

Three types of unstructured grids were created from the MB grids: Hexahedral, Prismatic, and Hybrid Tetrahedral (Prismatic in the boundary layer and Tetrahedral in the field). The hexahedral format preserves the individual cell structure of MB grids, but converts the file into finite element form with no IJK structure. Subdivision of hexahedral elements into prismatic and tetrahedral elements follows the sequence shown in Figure 4a. Each hex cell subdivides into 2 prism cells, and then each prism is split into 3 tetrahedra. A usable fully tetrahedral grid could not be created due to issues at the trailing edge of the wing. Groups of cells inside the boundary layer were distorted such that when subdivided into a negative volume would result (Figure 4b). The prisms did not have this issue, so only the hybrid grids were created. Negative volumes were also encountered for the prism subdivision on the Super Fine grid, so only Hex meshes are available at that level.

A summary comparison of the grid sizes for all levels and types is listed in Table 3. Note that suitable grid refinement sequences are available for unstructured cell- or node-based schemes. 


\section{Test Case Descriptions}

It is recognized that many of the DPW participants are derived from industry and may have limited time and resources to devote to this type of study. The test case specifications, as with the grid definitions, are set to encourage participation by restricting the number of cases to a manageable number while also providing a challenge to test the state of the art in CFD prediction capabilities. The DPW-V test cases contain a set of required and optional conditions:

\section{Case 1 - NASA Common Research Model (CRM) Wing-Body Common Grid Study:}

1. Grid Convergence study at Mach $=0.85, \mathrm{C}_{\mathrm{L}}=0.500( \pm 0.001)$

- Grid refinement series from the Common Grid Sequence consisting of at least four grid levels $\Rightarrow$ Target grids should range from 3 to 50 million unknowns.

- Chord Reynolds Number RE $=5 \times 10^{6}$ based on $\mathrm{C}_{\mathrm{REF}}=275.80$ in

- Reference Temperature $=100^{\circ} \mathrm{F}$

- Moment reference center is $X_{\mathrm{REF}}=1325.90 \mathrm{in}, \mathrm{Z}_{\mathrm{REF}}=177.95$ in

2. Optional Grid Convergence study using participant developed grids:

- All participants are encouraged to build their own grids using 'best practice' techniques

Case 2 - (Required) NASA Common Research Model (CRM) Wing-Body Buffet Study:

- $\quad$ Mach $=0.85$

- Drag Polar for alpha $=2.50^{\circ}, 2.75^{\circ}, 3.00^{\circ}, 3.25^{\circ}, 3.50^{\circ}, 3.75^{\circ}, 4.00^{\circ}$

- Medium Grid used in Case 1 from the Common Grid Sequence or participant developed grids

- Chord Reynolds Number $\mathrm{Rn}=5 \times 10^{6}$ based on $\mathrm{c}_{\mathrm{REF}}=275.80$ in

- Reference Temperature $=100^{\circ} \mathrm{F}$

Case 3 (Optional) - Turbulence Model Verification:

1. 2D Zero Pressure Gradient Flat Plate: $M=0.20 ; \mathrm{RE}_{\mathrm{L}}=5 \times 10^{6} ; \mathrm{T}_{\text {ref }}=540 \mathrm{R}$

2. 2D Bump-in-channel: $\quad \mathrm{M}=0.20 ; \mathrm{RE}_{\mathrm{L}}=3 \times 10^{6} ; \mathrm{T}_{\mathrm{ref}}=540 \mathrm{R}$

3. 2D NACA 0012 Airfoil: $\quad \mathrm{M}=0.15 ; \mathrm{RE}_{\mathrm{C}}=6 \times 10^{6} ; \mathrm{T}_{\mathrm{ref}}=540 \mathrm{R}$

All CRM simulations are to be "free air" with no wind tunnel walls or support system. The boundary layer is to be modeled as "fully turbulent" for all cases. No free or fixed laminar to turbulent transition is to be specified.

To collect a consistent set of data from each participant, template datasets were supplied. These templates request lift, drag (broken down by mechanical component), pitching moment, pressure distributions at specified span stations, trailing-edge separation locations, dimensions of the side-of-body separation bubble, grid family and sizes, turbulence model, computing platform and code performance, number of processors used, number of iterations required, etc. These workshops capture an extensive amount of information that serve as a snapshot of the industry capabilities of the time. For example, in the four workshops held thus far, one obvious trend is that the grid size has grown dramatically. The average size of the medium WB meshes in DPW-I through DPW-IV have been 3.2, 5.4, 7.8 and 10.9 million, respectively. This represents a growth rate of $\sim 17 \%$ per year during the eight years between DPW-I and DPW-IV. For DPW-V this trend was not continued in that the "Medium" mesh is approximately 5.1M nodes.

\section{Results}

The level of participation in DPW-V was excellent by many counts. Users submitted data from a wide variety of sources, code types, grid types, and turbulence models. Many performed studies which specifically addressed the effects of gridding and/or turbulence modeling with the same code. As mentioned above, the geometry, test cases, and data format were all uniformly controlled to facilitate the analysis.

\section{A. Participant Descriptions}

The Drag Prediction Workshop is open to any individual, group or organization that wishes to perform the calculations according to the specifications set out by the organizing committee. The response for DPW-V has increased somewhat from the previous workshop, following a trend of gradually increasing participation.

A total of 57 datasets were submitted from 22 different teams or organizations. Of these teams, they are broken down by location and type as follows: 
- 10 North America, 5 Europe, 6 Asia, 1 South America

- 9 Government, 5 Industry, 6 Academia, 2 Commercial

Note that one team submitted data for the turbulence modeling Case 3 only. For Case 1 and 2, the grid type and turbulence model breakdown includes:

$\begin{array}{lll}\text { - Grid Types: } & 5 & \text { Common Over } \\ & 7 & \text { Common Struct } \\ & 25 & \text { Common Unst } \\ & 20 & \text { Custom User G } \\ & & \\ \text { - Turbulence Models: } & 38 & \text { SA (all types) } \\ & 13 & \text { SST } \\ & 4 & \text { Goldberg RT } \\ & 1 & \text { EARSM } \\ & 1 & \text { Lag-RST }\end{array}$

All participants were asked to submit force/moment, pressure, and separation data in a standard format. The large number of datasets poses a challenge in the presentation of the data. Each dataset is assigned an Alphanumeric (including Greek) symbol type while colors and line types are used to denote grid or turbulence model type depending on context. All of the force/moment and pressure plots below follow the scheme listed in Table 4 .

\section{B. Case 1: CRM at Cruise Mach}

The first test case is focused on the grid refinement study for the CRM Wing-Body at $M=0.85$ and $\mathrm{C}_{\mathrm{L}}=0.500$. The trends with grid size for total drag are shown in Figure 5, broken out by grid type and turbulence model. Overall, the scatterband reduces considerably as the grid is refined, and the bulk of the results converge to a band about 10-15 counts wide. The relatively poor agreement for the Tiny and Coarse grid levels is to be expected, as they are below typical industry standards for grid resolution. There is no clear advantage of any one grid type in terms of a reduced scatter. With one exception, similar trends can be observed for the turbulence models. The Goldberg RT model (Datasets M, O, Q, and S) clearly predicts the drag to be higher, although some of the SST results ( $\mathrm{T}$ and $\mathrm{P}$ ) with the same code are high as well. The two other sets from this team $(\mathrm{N}$ and $\mathrm{P})$ which use the SST model compare well with the other SST results. Most of the SST results have a shallower trend with grid size and agree with each other very well even though they represent the results of six different codes and multiple grid types. Similar trends are seen in the Skin Friction and Pressure drag components, Figure 6 and Figure 7. The skin friction does not vary significantly with grid resolution, confirming that grid refinement beyond a certain level is not needed to resolve the boundary layer for most of the grids and turbulence models. Alpha for $C_{L}=0.500$ and pitching moment are shown in Figure 8. Other than a few outliers, the trends are very flat with grid size. Alpha falls generally in the range from $2.1^{\circ}-2.3^{\circ}$, and the spread in pitching moment is $\sim 0.02$. The latter represents a stabilizer incidence range of about $0.5^{\circ}$ for typical tail configurations.

A standard technique in grid convergence studies is to use the Richardson Extrapolation. As implemented here, a standard least squares curve fit is used with grid factor, $\mathrm{N}^{-2 / 3}$, where $\mathrm{N}$ is the number of unknowns. For second order codes the error should linearly decrease as long as the refinement extends into the asymptotic region. The Yintercept then estimates the theoretical infinite resolution (continuum) result. The extrapolations are shown in Figure 9. It is clear that some nonlinearity is still present in the curves, which would indicate that the asymptotic region has not yet been reached for the coarse grid levels because there are still changes in some flow features with grid refinement. At finer levels the behavior is more linear.

Also shown here for the first time are wind tunnel results from the NASA NTF and Ames tests, which warrants some discussion. Differences in the "test" set-up between Wind Tunnel and CFD are well known, and a few are listed below:

$\begin{array}{ll}\text { Wind Tunnel } & \underline{\text { CFD }} \\ \text { Walls } & \text { Free Air } \\ \text { Support System (Sting) } & \text { Free Air } \\ \text { Laminar/Turbulent (Tripped) } & \text { "Fully" Turbulent (usually) } \\ \text { Aeroelastic Deformation } & \text { Rigid 1g Shape } \\ \text { Measurement Uncertainty } & \text { Numerical Uncertainty and Error } \\ \text { Corrections for known effects } & \text { No Corrections }\end{array}$


Clearly there are potentially significant differences between what Wind Tunnel and CFD are measuring/computing. It is important to assess differences in magnitude between wind tunnel and CFD, but until the above variables are better addressed we should consider that the wind tunnel data are included for reference only.

As described above, the common grid study is a key feature of DPW-V. Figure 9a shows total drag coefficient results for all grids, while Figure $9 \mathrm{~b}$ shows only the Common Grids which use the exact same node distributions. A quite significant variation in the solutions remains, which may be due to the cell subdivisions into prisms and tetrahedra. So the data are further reduced to only hex-based grids - Structured, Unstructured, and Overset - in Figure 9c. Any remaining variation must be due to specifics of the CFD method coding, including turbulence model.

Figure 10a shows the angle of attack for $\mathrm{C}_{\mathrm{L}}=0.500$, while Figure $10 \mathrm{~b}$ shows the pitching moment. All the methods predict alpha to be too low compared to the wind tunnel - a result that has been present in all previous workshops. Part of the reason for this is wing aeroelastic bending, but it is likely not the entire reason. Pitching moment is also too negative, also at least partly from wing bending.

The continuum drag estimates are shown in Figure 11. The spread in the drag coefficient is 27.9 counts, while the standard deviation is 5.3 counts. These represent a small improvement from DPW-IV, which were 40.9 and 8.1 counts, respectively. Average and median $C_{D}$ are 0.02516 and 0.02496 , the difference reflecting the skewed nature of the distribution shown in the inset figure. The median solution is within about 4 counts of the wind tunnel data. Although the exact magnitude of the differences between wind tunnel and CFD described above are not known, it is still a good sign that the data agree reasonably well.

Pressure coefficients at six stations along the wing span are shown in Figure 12 for the Level 3 grid submissions. The level of scatter and agreement with wind tunnel data are generally very good although both tend to deteriorate as the span station progresses to the wing tip. The tunnel data tend to have lower leading edge suction peaks than the CFD results. This trend may be the result of aeroelastic deformation of the wing on the wind tunnel model, which would lower the tip incidence on a swept wing. Effects of grid refinement are shown in Figure 13 for Station $10(\eta=.5024)$. Note that fewer pressure datasets were provided for Levels 1,5 , and 6 , and that should be taken into account as it magnifies the decrease in scatterband at higher grid resolutions. There is no fundamental change in shock location with the finer grids. There are no observable trends with grid type or turbulence model in the pressure distributions.

\section{Case 2: CRM Buffet Study}

The second mandatory case is based on a buffet study to investigate the CFD predictions in an angle-of-attack range where significant flow separation is expected. This flight regime is of particular importance to determining aerodynamic loads and stability and control characteristics. Seven angles-of-attack were specified between 2.5 and $4.0^{\circ}$ at $0.25^{\circ}$ increments. Computed results of lift, drag, pitching moment, wing section pressure and skin friction coefficients at specified spanwise locations, and locations of flow separation on the wing and side of body were requested at each angle-of-attack. Over 50 data sets were provided by the Workshop participants for Case 2.

In assessing the quality of computed results it is desirable to have corresponding experimental data available for comparison. Unfortunately, the initial comparisons with experimental results from both the National Transonic Facility and the NASA Ames 11 Foot Wind Tunnel were disappointing. Studies reported in Refs. 62 and 63 have identified the primary causes for the disagreement between the computed and measured results. These included the effects of the swept-strut mounting system and most importantly the geometry of the wing used in the computational analysis. The CRM wing geometry used for both the Fourth and Fifth Drag Prediction Workshops was defined prior to the building and testing of the CRM wind tunnel model. Ideally the computational geometry should include the aeroelastic deformation of the experimental subject under the actual test conditions. This is not generally done at each test condition, but should be if the best possible correlation is desired. Typically the wind tunnel model is designed to deflect to the desired design shape at a single cruise point in terms of lift, Mach number, and dynamic pressure. Most, if not all CFD is done on that shape. The current CRM wind tunnel model was built to the design shape. The CRM geometry and grids represent the design shape, which in this case is the wind-off shape. During actual test conditions the model will deform under load.

To provide some measure for comparison a set of "pseudo" wind tunnel data was created. These "pseudo" data are based on NTF data for the wing-body configuration and computational results from Ref. 63 for a wing-body-tail configuration. The Ref. 63 results were for solutions using the Workshop geometry and solutions using a wing shape derived from the model deformation data from the NTF at the "cruise" conditions. NTF test data, "pseudo" test data, and computational results for the original geometry and the geometry with the measured twist are shown in Figure 14. The difference between the two computational solutions was applied to the NTF experimental results to generate the "pseudo" test data. For lift, the computational results with the measured twist are in reasonable 
agreement with the NTF data while the computational results using the Workshop geometry agrees well with the "pseudo" test data. The pitching moment data is significantly different in that the available computational results were for a wing-body-tail configuration while the test data is for a wing-body configuration. Nevertheless, to first order, the pitching moment increment due to twist should be applicable. Based results from Reference 63, it is anticipated that corrections for the effect of the wind tunnel model mounting system (if they have been available for the wing-body configuration) would have further increased the lift slightly and made the pitching moment more negative in the "pseudo" data. These "pseudo" data should somewhat represent what would have been measured if the wind tunnel model had assumed the "design" shape at the "cruise" condition. For purposes of the buffet study the drag differences were too small to warrant creating "pseudo" drag data.

Lift and pitching moment results from all the Workshop submittals, along with the "pseudo", NTF, and Ames test data are shown in Figure 15. Most of the solutions are clustered within a "fan" that gets progressively wider with increasing angle-of-attack. The exceptions are a group of solutions based on the Goldberg RT turbulence model, and those other solutions that also suffered an early massive flow separation.

All the solutions were examined to determine outliers, and if there was some defining characteristic that determined the quality of the solution. The outliers were defined as solutions that exhibited a break in lift prior to $4^{\circ}$ angle-of-attack, or exhibited drag considerably outside the norm of the other solutions. Outliers were seen in solutions from all grid families, and from SA, SST, and Goldberg RT turbulence models. Lift break, which is indicative of a large increase in flow separation, occurred as early as $3^{\circ}$ angle-of-attack in five solutions. Seven solutions exhibited a lift break between 3.25 and $3.5^{\circ}$, and a further nine solutions at $3.75^{\circ}$ angle-of-attack.

The source of the early break can be found by examining the separation data requested by the DPW organizing committee and provided by most participants. There is a tendency for some codes to predict a large separation bubble at the wing root trailing edge by the side of body (SOB), shown in Figure 16, while others preserved smooth flow virtually all of the way to the trailing edge. The predicted SOB separation bubble in these cases is large enough to be seen in the force and moment results, however the wind tunnel data do not exhibit any evidence of flow separation at the first row of pressures located at $\mathrm{BL}=151$, nor does it show an early lift break. All of the solutions identified with a separation bubble size greater than $\mathrm{BL}=151$ also exhibited a lift break below $4^{\circ}$ angle of attack and have been identified as outliers. This type of 3D corner flow separation continues to need more attention in turbulence model development.

Eliminating all the outliers as defined above, we have 26 solutions with lift and pitching moment characteristics shown in Figure 17. Even with all the outliers removed there is still an increasing spread of the lift and pitching moment with increasing angle-of-attack. At $4^{\circ}$ angle-of-attack the value of lift coefficient varies by 0.055 and the spread in pitching moment coefficient is 0.042! Note that for lift the solutions based on the SST turbulence model tend to be clustered at the lower half of the group and are closest to the "pseudo" test data. These solutions are also characterized by a slightly more forward shock position compared to the SA solutions. The SA solutions, which encompass several different flavors of the SA turbulence model, span the spread although most tend to be in the higher portion of the group. The solutions based on the EARSM and LagRST turbulence model are somewhere in the middle. Each one of these solutions on its own is a valid solution, yet as angle-of-attack increases and the resulting degree of flow separation increases, the variation between solutions increases. Which, if any, is most correct? Further inspection could identify and remove more outliers, but the spread is likely to remain.

The drag characteristics of the remaining solutions are shown in Figure 18. Also shown are test results from three repeat runs at both the NTF and Ames wind tunnels. Details of these tests and a description of the corrections applied to the experimental data can be found in Ref. 47. "Pseudo" drag is not shown in that the twist corrections are of the same order as the spread between repeat runs and would add nothing to the comparison. The drag characteristics are plotted in terms of the idealized profile drag defined as:

$$
\mathrm{C}_{\mathrm{DP}}=\mathrm{C}_{\mathrm{D}}-\mathrm{C}_{\mathrm{L}}^{2} /(\pi \mathrm{AR})
$$

Plotting $C_{D P}$ instead of $C_{D}$ can be very useful as its variation with $C_{L}$ is significantly diminished, and therefore, the scale of the plot can be greatly increased. The spread of the drag values is largely driven by the increasing spread of lift with increasing angle-of-attack. Note that the spread of the drag values at low lift coefficients is of the same order as the spread of the test data between the two tunnels.

The significant variations in lift and pitching moment seen in the various solutions at each angle-of-attack are driven largely by shock location and by the amount of trailing edge separation. The pressure distributions shown in Figure 19 give some insight into these characteristics. At $2.75^{\circ}$ angle-of-attack, except for solutions based on the Goldberg RT turbulence model, very little trailing edge separation, less than $2 \%$ chord, exists. The lift and pitching moment variation here is driven mainly by differences in shock location. By $3.0^{\circ}$ angle-of-attack, as seen in Figure 
20, there is a significant amount of trailing edge separation for most solutions except for the one based on the EARSM turbulence model - somewhat more separation for the SST solutions, more variation among the various versions of the SA turbulence model. By $4.0^{\circ}$ angle-of-attack, as seen in Figure 20, there is a massive amount of trailing edge separation with significantly different patterns between solutions. There does not appear to be any single clear pattern.

The chaotic situation at these high angles-of-attack may be physical as well as computational. One must ask if steady Reynolds Averaged Navier-Stokes is adequate for modeling this flow regime. Will URANS (Unsteady Reynolds Averaged Navier-Stokes) be adequate, or must one go to an eddy-resolving method such as DES (Detached Eddy Simulation) to accurately simulate this flow regime? In addition to further CFD research in this area, detailed experimental measurements that adequately capture the flow separation and unsteadiness on these type configurations must also be acquired.

\section{Case 3: Turbulence Model Verification Study}

A unique feature of this drag prediction workshop was the addition of an optional set of simple test cases from the online Turbulence Model Resource website ${ }^{61}$. These test cases were designed to discriminate between turbulence models and their coding implementations through rigorous grid convergence studies. In other words, different CFD codes that have implemented a given turbulence model as intended should produce nearly the same result as the grid is refined for these cases. This same type of rigorous verification testing is currently not possible for complex configurations such as the CRM.

In this study, designated as Case 3, three 2-D cases were selected: flat plate, bump, and NACA 0012 airfoil. Ten participants - representing 8 of the 21 teams who participated in cases 1 and 2 - submitted results, which were compared with reference solutions from the online resource (using CFL3D). Table 5 summarizes the entries. For convenience, a unique ID was assigned for these "turbulence modeling" cases. The table shows the linkage between this ID and the corresponding ID(s) used in the CRM part of the workshop. One dataset (indicated by a *) was corrected after the workshop, and two datasets (indicated by a **) were added after the workshop. Unfortunately, several of the participants submitted the requested information on only a single grid level, so it is not clear where their solutions were heading as the grids were refined. All participants used a version of either the SA or SST turbulence models. Note that SST uses strain-based production terms, and SST-V uses vorticity-based approximate production terms. In the table, the model(s) used are indicated, along with the grid levels employed ( $\mathrm{f}=$ finest, $\mathrm{m}=$ medium, $\mathrm{c}=$ coarse). All grids (except those used by T7) were the same structured / hexahedral grids, which were successively coarsened by removing every other point in each coordinate direction.

Case 3.1 Flat Plate: The zero-pressure-gradient flat plate case was computed using $M=0.2, \operatorname{Re}_{\mathrm{L}}=5$ million, where $\mathrm{L}=1$ nondimensional unit and the total plate length was $2 \mathrm{~L}$. Figure 21 shows wall skin friction coefficient using SA at location $\mathrm{x}=0.97$, as a function of $\mathrm{h}$, a measure of average grid spacing. (The online website notes that quantities of interest rarely converge consistently at second order in practice, even for a nominally second-order code on these simple problems, so $\mathrm{h}$ is chosen here for convenience.) Although T1 and T3 only used a single grid size, their results were clearly inconsistent with the majority of the results. T4 also only used a single grid size, but its results agreed well with the collective. Although not shown here, $\mathrm{C}_{\mathrm{f}}$ results at other locations followed a similar trend.

Using SST, four different participants agreed well with each other as the grid was refined, Figure 22. (Note that when computing the flat plate, SST and SST-V are indistinguishable because strain and vorticity are the same.) T1 was again noticeably different than the collective. T3 was not run using an SST model.

Case 3.2 Bump: The bump case was useful because it tested more features than the simple flat plate, including the use of non-Cartesian geometry and grid topology, as well as non-zero pressure gradient. The bump itself (with maximum nondimensional height of 0.05 ) extended from $0.3<\mathrm{x}<1.2$. The solid wall extended from $0<\mathrm{x}<1.5$. Flow conditions were $\mathrm{M}=0.2$ and $\mathrm{Re}=3$ million per unit length.

Again, wall skin friction coefficient at particular locations were a useful metric for evaluating the expected solution for a given turbulence model. Figure 23 shows $\mathrm{C}_{\mathrm{f}}$ as a function of $\mathrm{h}$ for the $\mathrm{SA}$ model at $\mathrm{x}=0.6322$. Results at other locations yielded similar conclusions. Once again, T1 and T3 were outliers compared to the majority of results. In addition, for this case $\mathrm{T} 5, \mathrm{~T} 6$, and the original $\mathrm{T} 2$ submissions produced a noticeably different trend from the collective. Subsequently, the reason for the discrepancy was discovered to be the method used to compute minimum distance function (distance to the nearest wall). The T5, T6, and early T2 results used an approximate method. For example, T2 summed the distance by following along grid lines. When grid lines are not exactly normal to the surface, this procedure introduces errors. Subsequently using a more accurate computation of minimum distance function, T2's corrected result aligned well with the collective. 
Figure 24 shows a close-up of skin friction coefficient over the bump (near its peak) for SA. All results except T3 used the fine (f) grid. Although relatively small, the level of disagreement between participant results is clearly visible. The $\mathrm{C}_{\mathrm{f}}$ curves predicted by participants $\mathrm{T} 2, \mathrm{~T} 4, \mathrm{~T} 10$, and $\mathrm{T} 11$ are nearly indistinguishable.

For the bump case, the particular version of SST made a difference in results, as shown in Figure 25. Although not significantly different, SST-V yielded slightly lower values of $\mathrm{C}_{\mathrm{f}}$ at this location than SST. All participants except for T1 were consistent with each other.

Case 3.3 Airfoil: The NACA 0012 case was computed at $\mathrm{M}=0.15, \mathrm{Re}=6$ million per unit chord, and three different angles of attack: 0,10 , and $15 \mathrm{deg}$. Although this case represented a more aerodynamically realistic configuration than the other two cases, it turned out to be more difficult to draw firm conclusions. It may be necessary to include even finer grids than $1793 \times 513$ in future studies. Selected results are only shown here for AoA $=15$ deg. General conclusions from other angles of attack were similar.

As shown in Figure 26, for the NACA 0012, all participant results - including T1 and T3 - appeared to be consistent using the SA model, in spite of uncertainties in the particular results that did not include grid studies. (Note that T7 used a custom grid with anisotropic h-adaptation and a discontinuous Galerkin algorithm. Thus, its results are not straightforward to plot along with other results; it is not of the same family and its point count was not provided. Currently, it is arbitrarily plotted using h of approximately 0.002.) For the SST and SST-V models in Figure 27, the drag coefficient was consistent among the participants, but the lift coefficient exhibited larger variation. However, the lift coefficient was also changing significantly with grid refinement, even on the finest grid, so it is difficult to draw firm conclusions without a grid study that includes even finer grids. At this level of detail, it was also impossible to detect different trends between SST and SST-V.

Although not shown, submitted results for NACA 0012 surface pressure coefficient and surface skin friction coefficient were generally consistent among participants for a given turbulence model, with the exception of participants T3 and T7. It is possible that these particular results were post-processed incorrectly for the workshop.

In summary, the turbulence model verification study was a very useful exercise. Using simple well-defined test cases (flat plate and bump) along with grid convergence studies, potential differences in turbulence modeling implementations were quickly uncovered. Use of a NACA 0012 airfoil test case was less enlightening, and may require the use of finer grids in future studies. For the flat plate and bump cases, T1 and T3 were consistently different from the collective. However, these participants did not perform grid studies, so it is not clear whether the inconsistencies were due to modeling differences, discretization errors, or a combination of both. The study also helped to isolate differences due to a particular cause: the use of an approximate minimum distance function. This was shown to introduce errors that could be an important factor when using complex grids on realistic configurations. The study further demonstrated that small but quantifiable differences can be expected between two commonly used forms of the SST model. Using simple problems to isolate and identify these levels of disparities may eventually help to explain why different codes yield different results when using ostensibly the same turbulence model on complex problems like the CRM.

\section{Conclusions}

The fifth AIAA CFD Drag Prediction Workshop was held in conjunction with the $30^{\text {th }}$ AIAA Applied Aerodynamics conference in June, 2012. The event was well attended by a diverse group of expert CFD practitioners from four continents representing government, industry, academia, and commercial code development institutions. This workshop focused on a common grid study for the NASA Common Research Model wing-body configuration, including single point grid convergence and high-alpha buffet conditions. An optional turbulence model verification study was also included.

A total of 57 Reynolds Average Navier Stokes datasets were provided on structured, overset, and unstructured grids. Of these, 37 used common grids all derived from the identical field of points regardless of grid type. For the Case 1 grid convergence study, a Richardson Extrapolation was performed to estimate continuum results. Total scatter and standard deviation were reduced from DPW-IV. Comparison to wind tunnel data is reasonable, within about 4 counts to the median solution. However, since the wind tunnel test and CFD problem setups are inherently different, there is some question as to how well they should agree. There are no clear breakouts with grid type or turbulence model, with the exception of the Goldberg RT model which predicted higher drag than the bulk of the other solutions - especially for the coarser grids.

For the Case 2 buffet study, a set of outliers were observed that had uncharacteristically large wing trailing edge separation at the side of body which contributed to an early lift break. This break is definitely not present in the wind tunnel data. For the solutions minus the outliers, the grouping of forces was relatively tight at $\alpha=2.5^{\circ}$. In general, $\mathrm{C}_{\mathrm{M}}$ was predicted to be too negative, partly due to known geometry differences including steady aeroelastic 
effects. The later effect is observed in the wing pressure distributions which agree well over the inboard wing but deteriorate outboard. Variations in the forces spread significantly at $\alpha=4.0^{\circ}$ due to differences in shock induced separation predicted on the wing. It is not known whether the flow is steady for those conditions and whether steady RANS methods are adequate. Studies with unsteady RANS or DES may be needed to confirm these effects, as well as experiments designed to measure unsteady flows. The SOB separation bubble characteristic of the outlier solutions needs further study and development of turbulence models for corner flow geometries.

The Case 3 turbulence model verification study showed generally consistent results for a given turbulence model, although potential differences in the implementation of some models were uncovered. An approximate minimum distance function was shown to cause differences that could be significant when computing on realistic configurations. Using this type of simple problem can help to explain conflicting results when using the same turbulence model in different codes.

\section{References}

1. 1st AIAA CFD Drag Prediction Workshop, Anaheim, CA, June 2001, http://aaac.larc.nasa.gov/tsab/cfdlarc/aiaadpw/Workshop1/workshop1.html, accessed 11 November 2012.

2. Redeker, G., "DLR-F4 Wing-Body Configuration," A Selection of Experimental Test Cases for the Validation of CFD Codes, number AR-303, pages B4.1-B4.21. AGARD, August 1994.

3. Levy, D. W., Vassberg, J. C., Wahls, R. A., Zickuhr, T., Agrawal, S., Pirzadeh, S., and Hemsch, M. J., "Summary of data from the first AIAA CFD Drag Prediction Workshop," AIAA Journal of Aircraft, 40(5):875-882, Sep-Oct 2003.

4. Hemsch, M. J., "Statistical Analysis of CFD Solutions from the Drag Prediction Workshop," AIAA paper 2002-0842, 40" AIAA Aerospace Sciences Meeting \& Exhibit, Reno, NV, January 2002.

5. Rakowitz, M., Eisfeld, B., Schwamborn, D., and Sutcliffe, M., "Structured and Unstructured Computations on the DLR-F4 Wing-Body Configuration," AIAA Journal of Aircraft, 40(2):256-264, 2003.

6. Mavriplis, D. J. and Levy, D. W., "Transonic Drag Predictions Using an Unstructured Multigrid Solver," AIAA Journal of Aircraft, 42(4):887-893, 2005.

7. Pirzadeh, S. Z. and Frink, N. T., "Assessment of the Unstructured Grid Software TetrUSS for Drag Prediction of the DLRF4 Configuration," AIAA paper 2002-0839, 40th AIAA Aerospace Sciences Meeting \& Exhibit, Reno, NV, January 2002.

8. Vassberg, J. C., Buning, P. G., and Rumsey, C. L., "Drag Prediction for the DLR-F4 Wing/Body Using OVERFLOW and CFL3D on an Overset Mesh," AIAA Paper 2002-0840, 40th AIAA Aerospace Sciences Meeting \& Exhibit, Reno, NV, January 2002.

9. 2nd AIAA CFD Drag Prediction Workshop, Orlando, FL, June 2003, http://aaac.larc.nasa.gov/tsab/cfdlarc/aiaadpw/Workshop2/workshop2.html, accessed 11 November 2012.

10. Laflin, K. R., Vassberg, J. C., Wahls, R. A., Morrison, J. H., Brodersen, O., Rakowitz, M., Tinoco, E. N., and Godard, J., "Summary of Data from the Second AIAA CFD Drag Prediction Workshop," AIAA Journal of Aircraft, 42(5):1165-1178, 2005.

11. Hemsch, M. and Morrison, J., "Statistical analysis of CFD solutions from 2nd Drag Prediction Workshop," AIAA Paper 2004-0556, 42nd AIAA Aerospace Sciences Meeting and Exhibit, Reno, NV, January 2004.

12. Pfeiffer, N., "Reflections on the Second Drag Prediction Workshop," AIAA Paper 2004-0557, 42nd AIAA Aerospace Sciences Meeting and Exhibit, Reno, NV, January 2004.

13. Brodersen, O. P., Rakowitz, M., Amant, S., Larrieu, P., Destarac, D., and Suttcliffe, M., "Airbus, ONERA and DLR Results from the Second AIAA Drag Prediction Workshop," AIAA Journal of Aircraft, 42(4):932-940, 2005.

14. Langtry, R. B., Kuntz, M., and Menter, F., "Drag Prediction of Engine-Airframe Interference Effects with CFX-5," AIAA Journal of Aircraft, 42(6):1523-1529, 2005.

15. Sclafani, J., DeHaan, M. A., and Vassberg, J. C., "OVERFLOW Drag Predictions for the DLR-F6 Transport Configuration: A DPW-II Case study," AIAA Paper 2004-0393, 42nd AIAA Aerospace Sciences Meeting and Exhibit, Reno, NV, January 2004.

16. Rumsey, C. Rivers, M., and Morrison, J., "Study of CFD Variations on Transport Configurations from the 2nd AIAA Drag Prediction Workshop,” AIAA Paper 2004-0394, 42nd AIAA Aerospace Sciences Meeting and Exhibit, Reno, NV, January 2004.

17. Wutzler, K., “Aircraft Drag Prediction using Cobalt,” AIAA Paper 2004-0395, 42nd AIAA Aerospace Sciences Meeting and Exhibit, Reno, NV, January 2004.

18. May, G., Van derWeide, E., Jameson, A., and Shankaran, S., "Drag Prediction of the DLR-F6 Configuration," AIAA Paper 2004-0396, 42nd AIAA Aerospace Sciences Meeting and Exhibit, Reno, NV, January 2004.

19. Kim, Y., Park, S., and Kwon, J., "Drag prediction of DLR-F6 using the turbulent Navier-Stokes calculations with multigrid," AIAA Paper 2004-0397, 42nd AIAA Aerospace Sciences Meeting and Exhibit, Reno, NV, January 2004.

20. Yamamoto, K., Ochi, A., Shima, E., and Takaki, R., "CFD Sensitivity to Drag prediction on DLR-F6 Configuration by Structured Method and Unstructured Method," AIAA Paper 2004-0398, 42nd AIAA Aerospace Sciences Meeting and Exhibit, Reno, NV, January 2004.

21. Tinoco, E. and Su, T., "Drag Prediction with the Zeus/CFL3D System," AIAA Paper 2004-0552, 42nd AIAA Aerospace Sciences Meeting and Exhibit, Reno, NV, January 2004.

12

American Institute of Aeronautics and Astronautics 
22. 3rd AIAA CFD Drag Prediction Workshop, San Francisco, CA, June 2006, http://aaac.larc.nasa.gov/tsab/cfdlarc/aiaadpw/Workshop3/workshop3.html, accessed 11 November 2012.

23. Vassberg, J. C., Sclafani, A. J., and DeHaan, M. A., "A Wing-Body Fairing Design for the DLR-F6 Model: A DPW-III Case Study," AIAA Paper 2005-4730, AIAA 23rd Applied Aerodynamics Conference, Toronto, Canada, June 2005.

24. Vassberg, J. C., Tinoco, E. N., Mani, M., Brodersen, O. P., Eisfeld, B., Wahls, R. A., Morrison, J. H., Zickuhr, T., Laflin, K. R., and Mavriplis, D. J., "Abridged Summary of the Third AIAA CFD Drag Prediction Workshop," AIAA Journal of Aircraft, 45(3):781-798, May-June 2008.

25. Vassberg, J. C., Tinoco, E. N., Mani, M., Brodersen, O. P., Eisfeld, B., Wahls, R. A., Morrison, J. H., Zickuhr, T., Laflin, K. R., and Mavriplis, D. J., "Summary of DLR-F6 Wing-Body Data from the Third AIAA CFD Drag Prediction Workshop," RTO AVT-147 Paper 57, RTO AVT-147 Symposium, Athens, Greece, December 2007.

26. Morrison, J. H. and Hemsch, M. J., "Statistical Analysis of CFD Solutions from the Third AIAA Drag Prediction Workshop," AIAA Paper 2007-0254, 45th AIAA Aerospace Sciences Meeting and Exhibit, Reno, NV, January 2007.

27. Tinoco, E. Winkler, N., C., Mani, M., and Venkatakrishnan, V., "Structured and Unstructured Solvers for the 3rd CFD Drag Prediction Workshop," AIAA Paper 2007-0255, 45th AIAA Aerospace Sciences Meeting and Exhibit, Reno, NV, January 2007.

28. Mavriplis, D. J., "Results from the 3rd Drag Prediction Workshop Using the NSU3D Unstructured Mesh Solver," AIAA Paper 2007-0256, 45th AIAA Aerospace Sciences Meeting and Exhibit, Reno, NV, January 2007.

29. Sclafani, A. J., Vassberg, J. C., Harrison, N. A., DeHaan, M. A., Rumsey, C. L., Rivers, S. M., and Morrison, J. H., "Drag Predictions for the DLR-F6 Wing/Body and DPW Wings Using CFL3D and OVERFLOW on an Overset Mesh," AIAA Paper 2007-0257, 45th AIAA Aerospace Sciences Meeting and Exhibit, Reno, NV, January 2007.

30. Brodersen, O., Eisfeld, B., Raddatz, J., and Frohnapfel, P., "DLR Results from the Third AIAA CFD Drag Prediction Workshop," AIAA Paper 2007-0259, 45th AIAA Aerospace Sciences Meeting and Exhibit, Reno, NV, January 2007.

31. Tinoco, E. N., Venkatakrishnan, V., Winkler, C., and Mani M., "Structured and Unstructured Solvers for the Third AIAA CFD Drag Prediction Workshop," AIAA Journal of Aircraft, 45(3):738-749, May-June 2008.

32. Mavriplis, D. J., "Third Drag Prediction Workshop Results Using NSU3D Unstructured Mesh Solver," AIAA Journal of Aircraft, 45(3):750-761, May-June 2008.

33. Sclafani, A. J., Vassberg, J. C., Harrison, N. A., Rumsey, C. L., Rivers, S. M., and Morrison, J. H., "CFL3D / OVERFLOW Results for DLR-F6 Wing/Body and Drag Prediction Workshop Wing,” AIAA Journal of Aircraft, 45(3):762-780, MayJune 2008.

34. Murayama, M. and Yamamoto, K., "Comparison Study of Drag Prediction by Structured and Unstructured Mesh Method," AIAA Journal of Aircraft, 45(3):799-822, May-June 2008.

35. Brodersen, O., Eisfeld, B., Raddatz, J., and Frohnapfel, P., "DLR results from the third AIAA Computational Fluid Dynamics Drag Prediction Workshop," AIAA Journal of Aircraft, 45(3):823-836, May-June 2008.

36. Eliasson, P. and Peng, S.-H., "Drag Prediction for the DLR-F6 Wing-Body Configuration Using the Edge Solver," AIAA Journal of Aircraft, 45(3):837-847, May-June 2008.

37. Mavriplis, D. J., Vassberg, J. C., Tinoco, E. N., Mani, M., Brodersen, O. P., Eisfeld, B., Wahls, R. H., Morrison, J., Zickuhr, T., Levy, D., and Murayama, M., "Grid quality and Resolution Issues from the Drag Prediction Workshop Series," AIAA Journal of Aircraft, 46(3):935-950, 2009.

38. $4^{\text {th }}$ AIAA CFD Drag Prediction Workshop, San Antonio, TX, June 2009. http://aaac.larc.nasa.gov/tsab/cfdlarc/aiaadpw/Workshop4/workshop4.html, aiaadpw@ gmail.com, accessed 11 November 2012.

39. Vassberg, J. C., DeHaan, M. A., Rivers, S. M., and Wahls, R. A., "Development of a Common Research Model for Applied CFD Validation Studies," AIAA Paper 2008-6919, 26th AIAA Applied Aerodynamics Conference, Hawaii, HI, August 2008.

40. Rivers, M. and Dittberner, A., "Experimental Investigations of the NASA Common Research Model," AIAA Paper 20104218, 28th AIAA Applied Aerodynamics Conference, Chicago, IL, June 2010.

41. Rivers, M. and Dittberner, A., "Experimental Investigations of the NASA Common Research Model in the NASA Langley National Transonic Facility and NASA Ames 11-Ft Transonic Wind Tunnel (Invited)," AIAA Paper 2011-1126, presented at the $49^{\text {th }}$ Aerospace Sciences Meeting, Orlando, FL, Jan 2011.

42. Common Research Model, http://commonresearchmodel.larc.nasa.gov/, Accessed 11 November 2012.

43. Vassberg, J., Tinoco, E., Mani, M., Rider, B., Zickuhr, T., Levy, D., Broderson, O., Eisfeld, B., Crippa, S., Wahls, R., Morrison, J., Mavriplis, D., Murayama, M., "Summary of the Fourth AIAA CFD Drag Prediction Workshop," AIAA 20104547, 28th AIAA Applied Aerodynamics Conference, Chicago, IL, June 2010.

44. Morrison, J., "Statistical Analysis of CFD Solutions from the Fourth Drag Prediction Workshop," AIAA 2010-4673, 28th AIAA Applied Aerodynamics Conference, Chicago, IL, June 2010.

45. Sclafani, A. J., Vassberg, J. C., Rumsey, C., DeHaan, M. A., and Pulliam, T. H., "Drag Prediction for the NASA CRM Wing/Body/Tail Using CFL3D and OVERFLOW on an Overset Mesh," AIAA Paper 2010-4219, 28th AIAA Applied Aerodynamics Conference, Chicago, IL, June 2010.

46. Hue, D., Gazaix, M., and Esquieu, S., "Computational Drag and Moment Prediction of the DPW4 Configuration with elsA," AIAA Paper 2010-4220, 28th AIAA Applied Aerodynamics Conference, Chicago, IL, June 2010.

47. Mani, M., Rider, B. J., Sclafani, A. J., Winkler, C., Vassberg, J. C., Dorgan, A. J., Cary, A., and Tinoco, E. N., "RANS Technology for Transonic Drag Prediction; a Boeing Perspective of the 4th Drag Prediction Workshop," AIAA Paper 20104221, 28th AIAA Applied Aerodynamics Conference, Chicago, IL, June 2010. 
48. Yamamoto, K., Tanaka, K., and Murayama, M., "Comparison Study of Drag Prediction for the 4th CFD Drag Prediction Workshop Using Structured and Unstructured Mesh Methods," AIAA Paper 2010-4222, 28th AIAA Applied Aerodynamics Conference, Chicago, IL, June 2010.

49. Brodersen, O., Crippa, S., Eisfeld, B., Keye, S., and Geisbauer, S., "DLR Results for the Fourth AIAA CFD Drag Prediction Workshop," AIAA Paper 2010-4223, 28th AIAA Applied Aerodynamics Conference, Chicago, IL, June 2010.

50. Eliasson, P., Peng, S., and Tysell, L., "Computations from the 4th Drag Prediction Workshop Using the Edge solver," AIAA Paper 2010-4548, 28th AIAA Applied Aerodynamics Conference, Chicago, IL, June 2010.

51. Li, G. and Zhou, Z., "Validation of a Multigrid-Based Navier-Stokes Solver for Transonic Flows," AIAA Paper 2010-4549, $28^{\text {th }}$ AIAA Applied Aerodynamics Conference, Chicago, IL, June 2010.

52. Mavriplis, D. J. and Long, M., "NSU3D Results for the Fourth AIAA Drag Prediction Workshop," AIAA Paper 2010-4550, 28th AIAA Applied Aerodynamics Conference, Chicago, IL, June 2010.

53. Lee-Rausch, E., Hammond, E., Nielsen, E., Pirzadeh, S., and Rumsey C., "Application of the FUN3D Unstructured-Grid Navier-Stokes Solver to the 4th AIAA Drag Prediction Workshop Cases," AIAA Paper 2010-4551, 28th AIAA Applied Aerodynamics Conference, Chicago, IL, June 2010.

54. Vos, J., Sanchi, S., Gehri, A., and Stephani, P., "DPW4 Results Using Different Grids, Including Near-Field/Far-Field Drag Analysis," AIAA Paper 2010-4552, 28th AIAA Applied Aerodynamics Conference, Chicago, IL, June 2010.

55. Hashimoto, A., Lahur, P., Murakami, K., and Aoyama, T., "Validation of Fully Automatic Grid Generation Method on Aircraft Drag Prediction," AIAA Paper 2010-4669, 28th AIAA Applied Aerodynamics Conference, Chicago, IL, June 2010.

56. Temmerman, L. and Hirsch, C. "Simulations of the CRM Configuration on Unstructured Hexahedral Grids: Lessons Learned from the DPW-4 Workshop,” AIAA Paper 2010-4670, 28th AIAA Applied Aerodynamics Conference, Chicago, IL, June 2010.

57. Chaffin, M. and Levy, D., "Comparison of Viscous Grid Layer Growth Rate of Unstructured Grids on CFD Drag Prediction Workshop Results," AIAA Paper 2010-4671, 28th AIAA Applied Aerodynamics Conference, Chicago, IL, June 2010.

58. Crippa, S., "Application of Novel Hybrid Mesh Generation Methodologies for Improved Unstructured CFD Simulations," AIAA Paper 2010-4672, 28th AIAA Applied Aerodynamics Conference, Chicago, IL, June 2010.

59. $5^{\text {th }}$ AIAA CFD Drag Prediction Workshop, http://aaac.larc.nasa.gov/tsab/cfdlarc/aiaa-dpw/, aiaadpw@gmail.com, accessed 11 November 2012.

60. Vassberg, J. C., "A Unified Baseline Grid about the Common Research Model Wing-Body for the Fifth AIAA CFD Drag Prediction Workshop," AIAA Paper 2011-3508, 29th AIAA Applied Aerodynamics Conference, Honolulu, HI, June 2011.

61. Rumsey, C., "Langley Research Center Turbulence Modeling Resource", http://turbmodels.larc.nasa.gov/, accessed 23 June 2012.

62. Rivers, M. and Hunter, C., "Support System Effects on the NASA Common Research Model," AIAA Paper 2012-707, January 2012.

63. Rivers, M., Hunter, C., and Campbell, R., "Further Investigation of the Support System Effects and Wing Twist on the NASA Common Research Model,” AIAA Paper 2012-3209, June 2012. 
Table 1. Reference Quantities for the CRM

\begin{tabular}{|c|c|c|c|c|}
\hline $\mathrm{S}_{\mathrm{ref}}$ & $594,720.0 \mathrm{in}^{2}$ & $=4,130 \mathrm{ft}^{2}\left[458.89 \mathrm{~m}^{2}\right]$ & $X_{\text {ref }}$ & $1,325.9$ in $[33.68 \mathrm{~m}]$ \\
\hline$S_{\text {trap }}$ & $576,000.0 \mathrm{in}^{2}$ & $=4,000 \mathrm{ft}^{2}\left[444.44 \mathrm{~m}^{2}\right]$ & $Y_{\text {ref }}$ & 468.75 in $[11.91 \mathrm{~m}]$ \\
\hline & $2,313.5$ in & $=192.8 \mathrm{ft} \quad[58.765 \mathrm{~m}]$ & $\mathrm{Z}_{\mathrm{ref}}$ & $177.95 \mathrm{in}[4.520 \mathrm{~m}]$ \\
\hline & 275.800 in & [4.8978 m] & $\Lambda_{\mathrm{c} / 4}$ & $35.0^{\circ}$ \\
\hline & 9.0 & & & 0.275 \\
\hline
\end{tabular}

Table 2. Gridding Guidelines (From DPW-IV)

1) Initial spacing normal to all viscous walls (RE Based on $\mathrm{C}_{\mathrm{REF}}=275.80$ "):

a) coarse: $\quad \mathrm{y}^{+} \sim 1.0 \quad \Delta \mathrm{y}_{1}=0.001478(\mathrm{RE}=5 \mathrm{M})$

b) medium: $\quad \mathrm{y}^{+} \sim 2 / 3 \quad \Delta \mathrm{y}_{1}=0.000985(\mathrm{RE}=5 \mathrm{M}), \quad \Delta \mathrm{y}_{1}=0.000273(\mathrm{RE}=20 \mathrm{M})$

c) fine: $\quad \mathrm{y}^{+} \sim 4 / 9 \quad \Delta \mathrm{y}_{1}=0.000657(\mathrm{RE}=5 \mathrm{M})$

d) extra-fine: $\mathrm{y}^{+} \sim 8 / 27 \quad \Delta \mathrm{y}_{1}=0.000438(\mathrm{RE}=5 \mathrm{M})$

2) Recommended: generate grids with 2 cell layers of constant spacing normal to viscous walls

3) Total grid size to grow $\sim 3 \mathrm{X}$ between each grid level for grid convergence cases

4) For structured meshes, this growth is $\sim 1.5 \mathrm{X}$ in each coordinate direction

5) Grid convergence cases must maintain the same grid family between grid levels, i.e. maintain the same stretching factors, same topology, etc.

6) Growth rate of cell sizes in the viscous layer should be $<1.25$.

7) Far field located at $\sim 100 \mathrm{C}_{\mathrm{REF}}$ 's for all grid levels.

8) For the Medium Baseline Grids:

a) Chordwise spacing for wing and tail leading edge (LE) and trailing edge (TE) $\sim 0.1 \%$ local chord.

b) Wing and tail Spanwise spacing at root $\sim 0.1 \%$ local semispan.

c) Wing and tail Spanwise spacing at tip $\sim 0.1 \%$ local semispan.

d) Cell size near fuselage nose and after-body $\sim 2.0 \%$ CREF.

9) For the Coarse and Fine Baseline Grids, the above values should be scaled accordingly.

10) Wing and Tail Trailing Edge Base:

a) Minimum of 8 cells across TE base for the coarse mesh

b) Minimum of 12 cells across TE base for the medium mesh

c) Minimum of 16 cells across TE base for the fine mesh

d) Minimum of 24 cells across TE base for the extra-fine mesh

11) Be multi-grid friendly

12) For unstructured grids designed for vertex based solvers, the spacings refer to inter-nodal spacings and the resulting grid sizes are expected to be similar to the structured grid sizes above. For unstructured grids for cellcentered solvers, the spacings refer to spacings between cell centers (or surface face centers), which corresponds approximately to a factor of 2 reduction in the overall number of surface points compared to the nodal solver case, for a triangular surface grid (this is based on triangle centroid separation distance of $2 / 3 \mathrm{~h}$ ). For tetrahedral cell-centered-solver meshes, the total number of grid points will be approximately $1 / 3$ of the numbers listed above.

Table 3. Metric Parameters for the Common Grids (Counts in Millions)

\begin{tabular}{|c|c|c|c|c|c|c|c|c|c|c|c|c|}
\hline & & & & & $\begin{array}{c}\text { Multiblock } \\
\text { Structured }\end{array}$ & Overset & \multicolumn{2}{|c|}{ Unstr. Hex } & \multicolumn{2}{|c|}{ Unstr. Prism } & \multicolumn{3}{|c|}{ Unstr. Hybrid } \\
\cline { 6 - 14 } Level & Name & Label & $\boldsymbol{\Delta}_{\mathbf{1}} \mathbf{y}^{+}$ & Points & Points & Cells & Nodes & Cells & Nodes & Tets & Prism & Nodes \\
\hline 1 & Tiny & $\mathrm{T}$ & 2.00 & 0.64 & 0.8 & 0.64 & 0.66 & 1.3 & 0.66 & 2.6 & 0.43 & 0.66 \\
\hline 2 & Coarse & $\mathrm{C}$ & 1.33 & 2.2 & 2.5 & 2.2 & 2.2 & 4.3 & 2.2 & 8.6 & 1.4 & 2.2 \\
\hline $\mathbf{3}$ & Medium & $\mathrm{M}$ & $\mathbf{1 . 0 0}$ & $\mathbf{5 . 1}$ & $\mathbf{5 . 7}$ & $\mathbf{5 . 1}$ & $\mathbf{5 . 2}$ & $\mathbf{1 0 . 2}$ & $\mathbf{5 . 2}$ & $\mathbf{2 0 . 8}$ & $\mathbf{3 . 3}$ & $\mathbf{5 . 2}$ \\
\hline 4 & Fine & $\mathrm{F}$ & 0.67 & 17.2 & 18.6 & 17.3 & 17.4 & 34.5 & 17.4 & 69.7 & 11.3 & 17.4 \\
\hline 5 & X-Fine & $\mathrm{X}$ & 0.50 & 40.9 & 43.3 & 40.9 & 41.2 & 81.8 & 41.2 & 166.1 & 26.4 & 41.2 \\
\hline 6 & S-Fine & $\mathrm{S}$ & 0.33 & 138.0 & 143.5 & 138.0 & 138.8 & --- & --- & --- & --- & --- \\
\hline
\end{tabular}


Table 4. DPW-V Case 1 and 2 Submissions and Participant Data Key

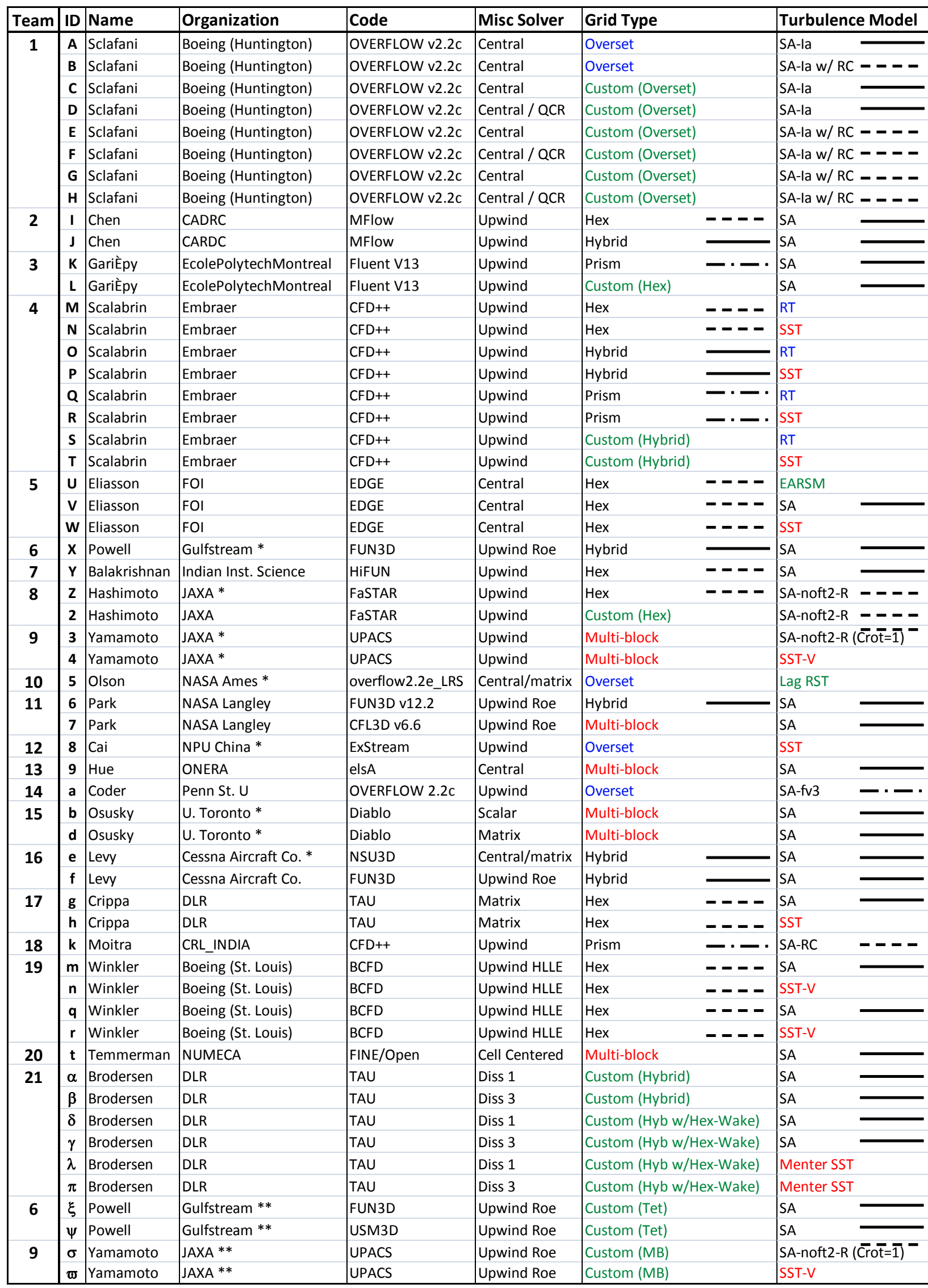

* Data Resubmitted After Workshop

** Cases Added After Workshop

16

American Institute of Aeronautics and Astronautics 
Table 5. Turbulence model verification (Case 3) participants

\begin{tabular}{|l|l|l|l|l|l|}
\hline ID & $\begin{array}{l}\text { Link to } \\
\text { CRM ID }\end{array}$ & CFD Code & Flat Plate & Bump & NACA 0012 \\
\hline T1 & I or J & MFlow & SA(f), SST(f) & SA(f), SST(f) & SA(f), SST(f) \\
\hline T2 & g or h & TAU & $\begin{array}{l}\text { SA(c-m-f), } \\
\text { SST(c-m-f) }\end{array}$ & $\begin{array}{l}\text { SA(c-m-f)*, } \\
\text { SST(c-m-f) }\end{array}$ & \\
\hline T3 & K or L & Fluent v13 & SA(m) & SA(m) & SA(m) \\
\hline T4 & 3 or 4 & UPACS & SA(f), SST-V(f) & SA(f), SST-V(f) & SA(f), SST-V(f) \\
\hline T5 & b & Diablo & SA(c-m-f) & SA(c-m-f) & SA(c-m-f) \\
\hline T6 & d & Diablo & SA(c-m-f) & SA(c-m-f) & SA(c-m-f) \\
\hline T7 & n/a & XFlow & & & SA(custom grid) \\
\hline T8 & m or n & BCFD** & $\begin{array}{l}\text { SA(c-m-f), } \\
\text { SST-V(c-m-f) }\end{array}$ & & \\
\hline T9 & f & FUN3D** & & SA(c-m-f), \\
\hline T10 & 6 or 7 & FUN3D & $\begin{array}{l}\text { SA(c-m-f), } \\
\text { SST-V(c-m-f), } \\
\text { SST(c-m-f) }\end{array}$ & $\begin{array}{l}\text { SA(c-m-f) }) \\
\text { SST(c-m-f) }\end{array}$ \\
\hline T11 & n/a & CFL3D & $\begin{array}{l}\text { SA(c-m-f), } \\
\text { SST-V(c-m-f), } \\
\text { SST(c-m-f) }\end{array}$ & $\begin{array}{l}\text { SA(c-m-f), } \\
\text { SST-V(c-m-f), SST(c- } \\
\text { m-f) }\end{array}$ \\
\hline
\end{tabular}

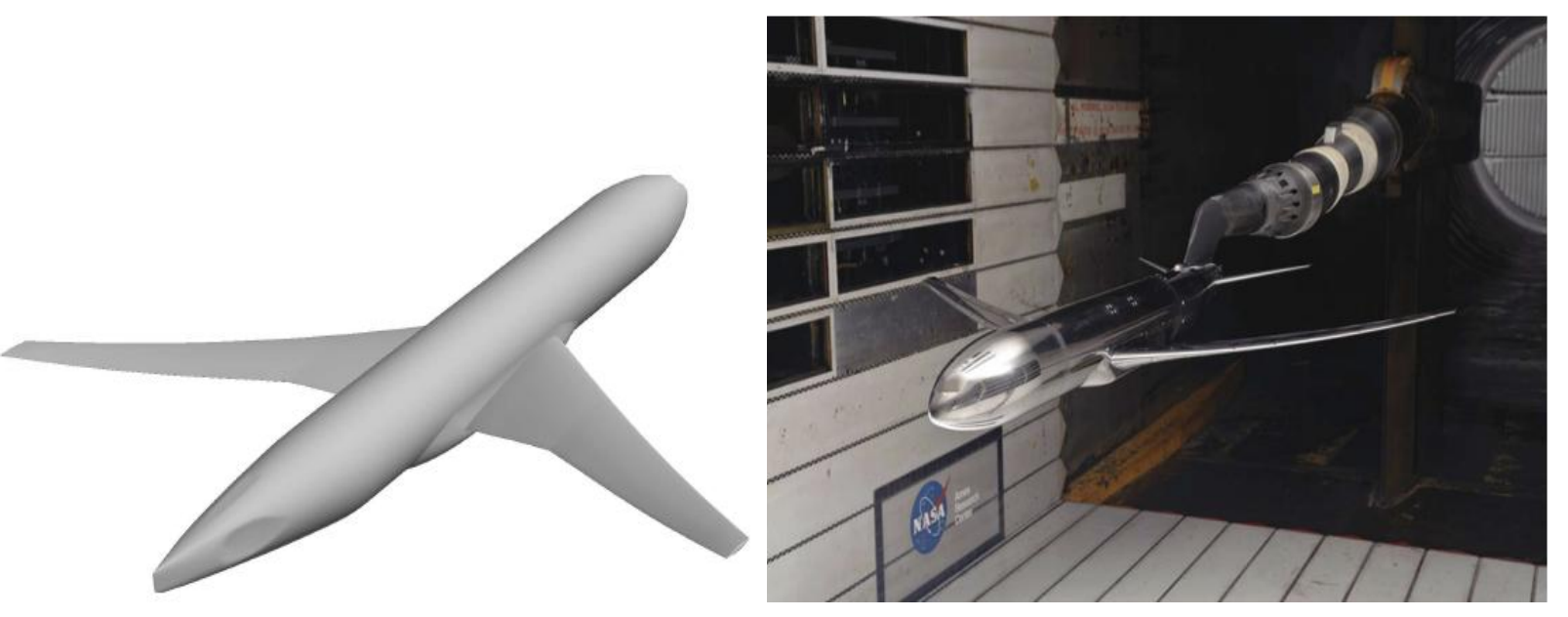

Figure 1. NASA Common Research Model Geometry for DPW-V Cases 1 and 2 


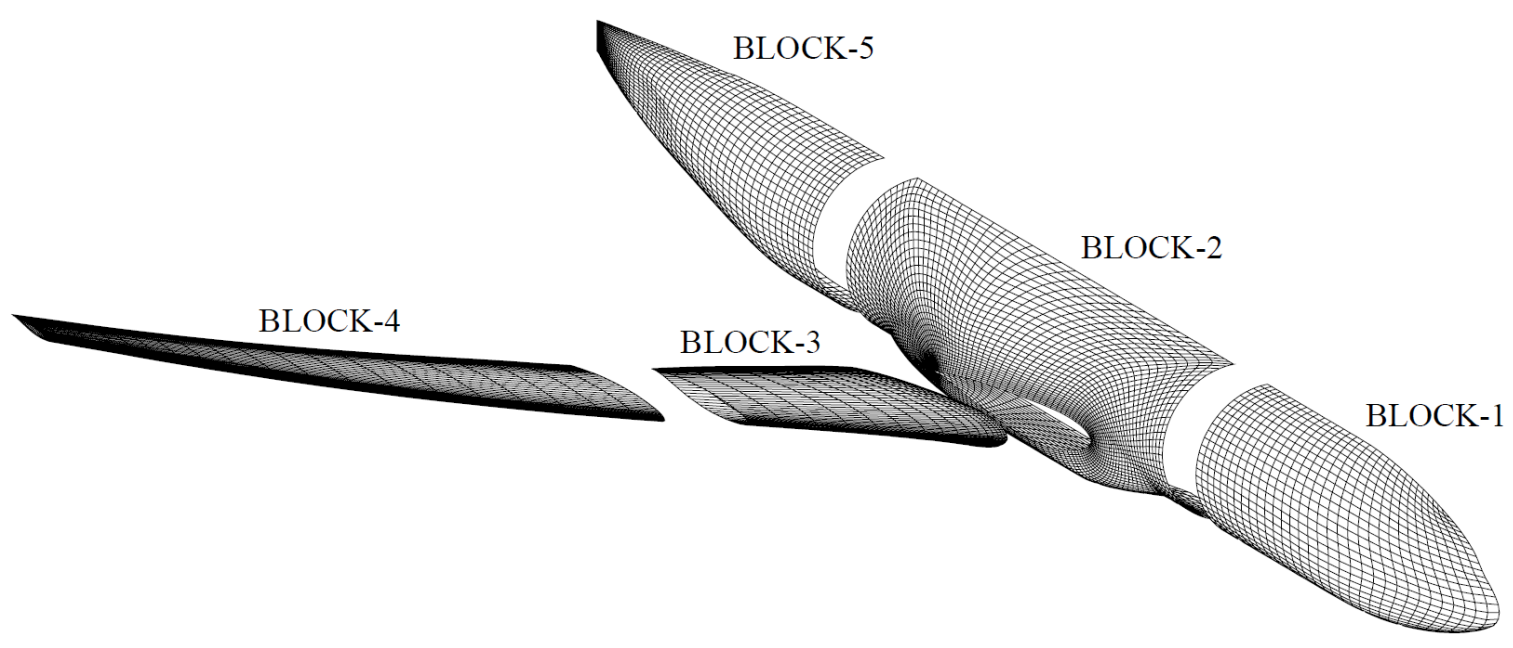

Figure 2. Block Topology for the CRM Wing-Body Multi-Block Grid Family.

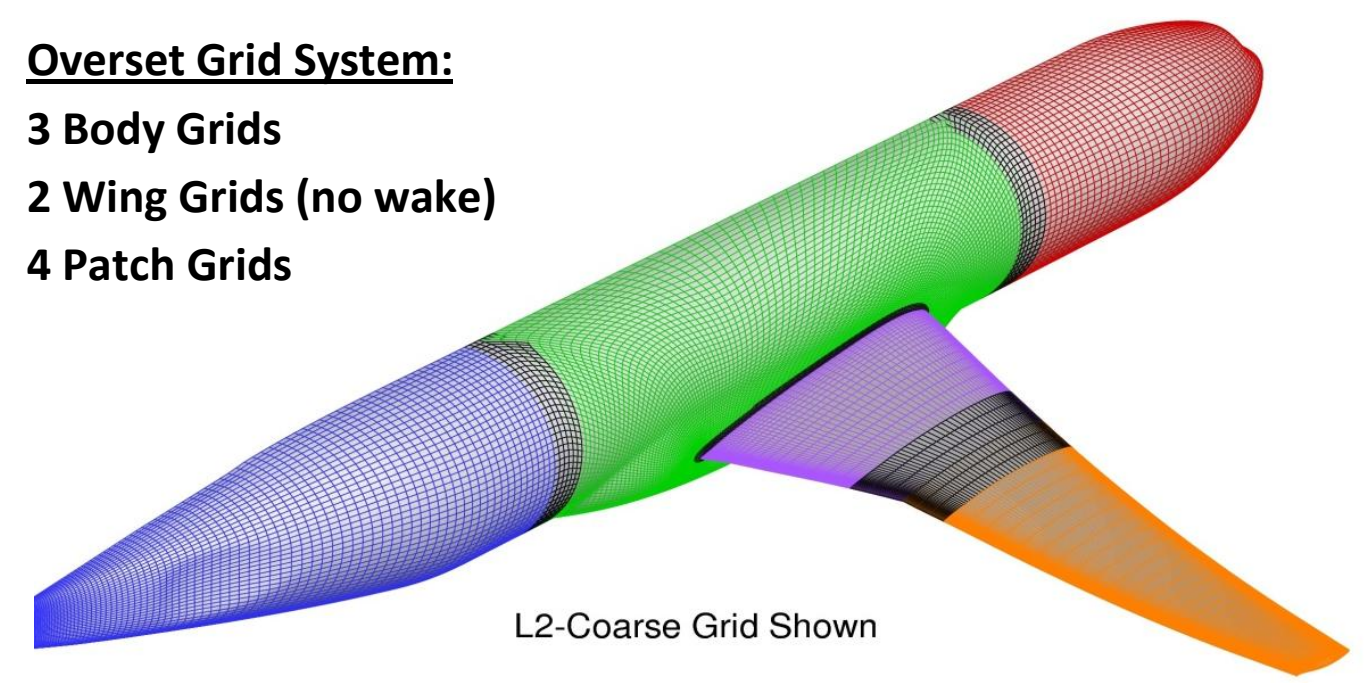

Figure 3. Overset Patch Grids Derived From the Multiblock Structured Grid.

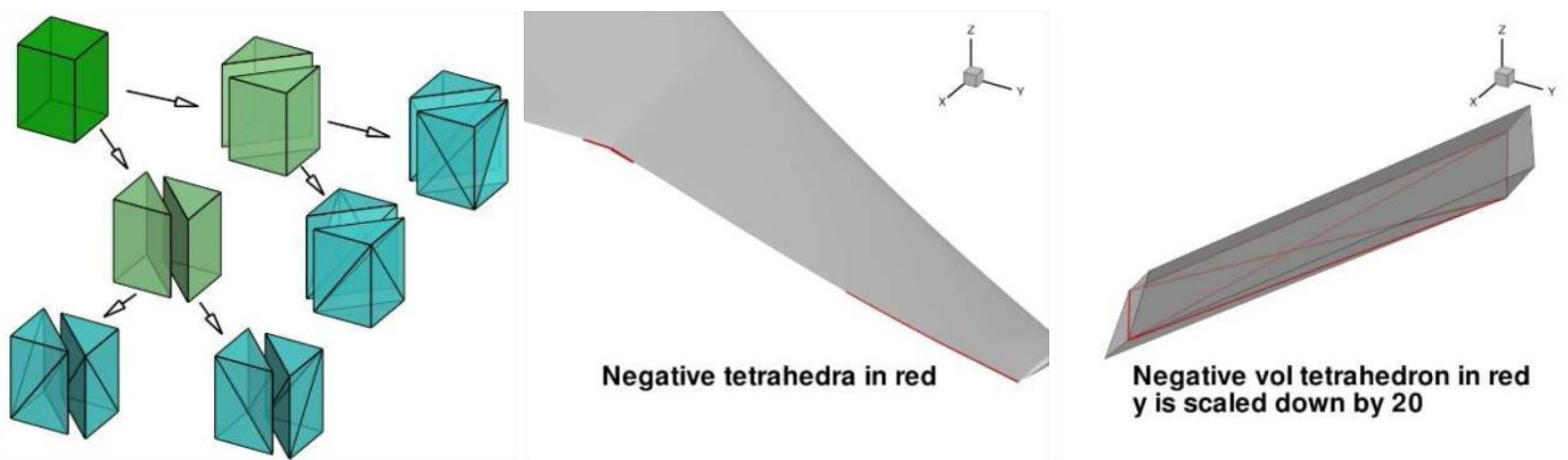

a) Hex to Prisms and Tets $\quad$ b) Issues with distorted high aspect ratio cells

Figure 4. Unstructured Grids Derived From the Multiblock Structured Grid. 

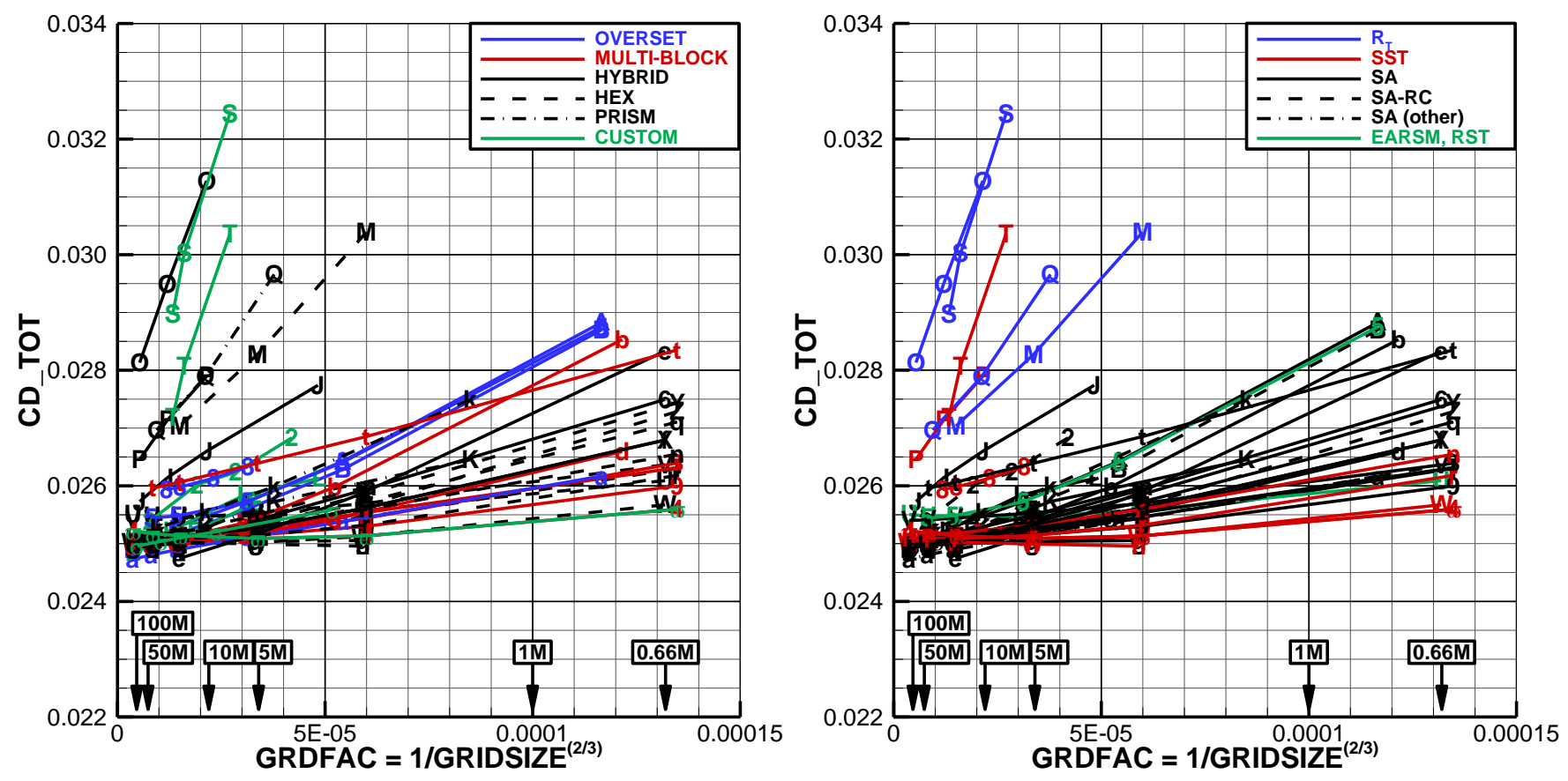

Figure 5. Case 1 Total Drag by Grid Type and Turbulence Model
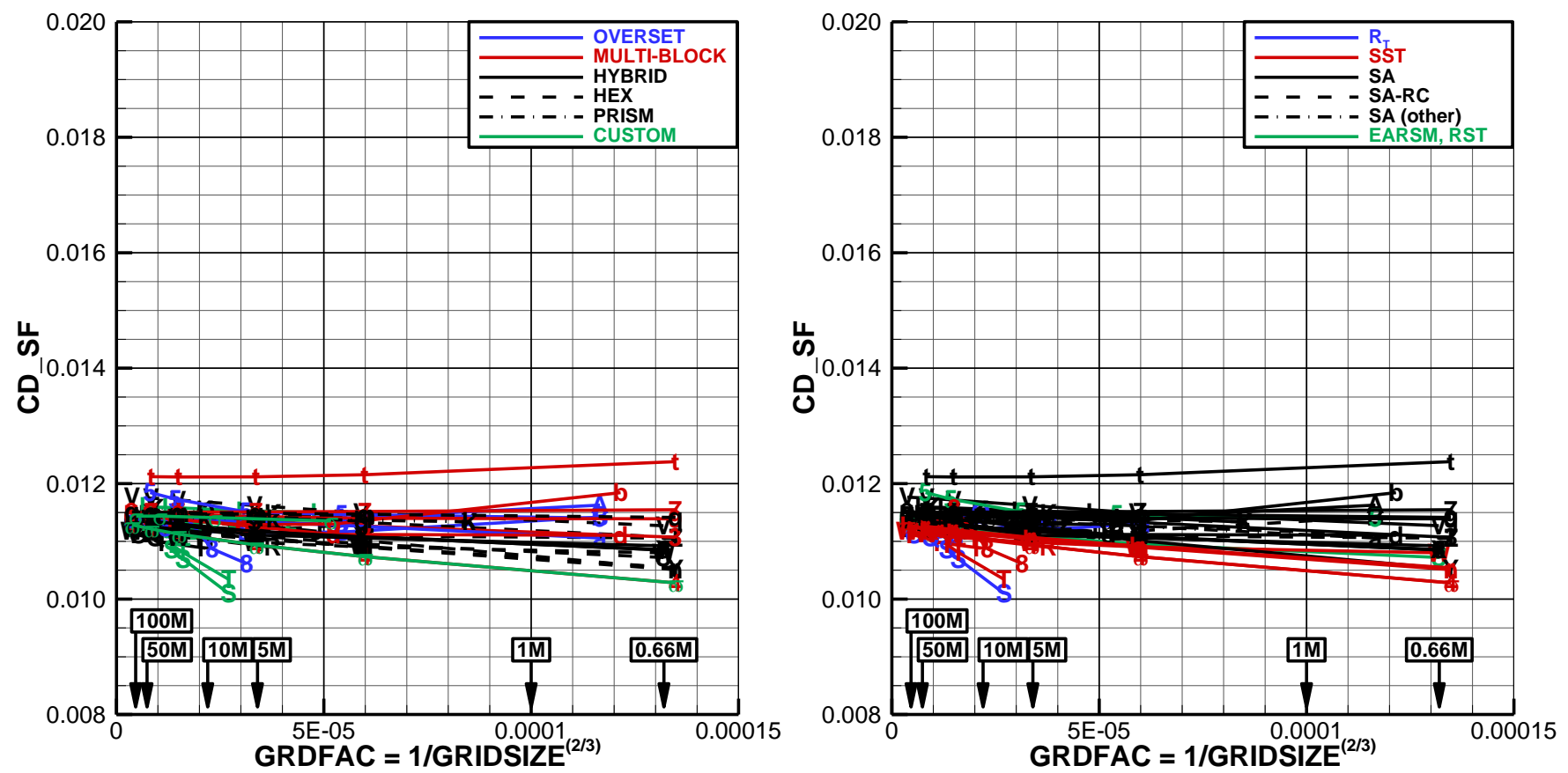

Figure 6. Case 1 Skin Friction Drag by Grid Type and Turbulence Model

American Institute of Aeronautics and Astronautics 

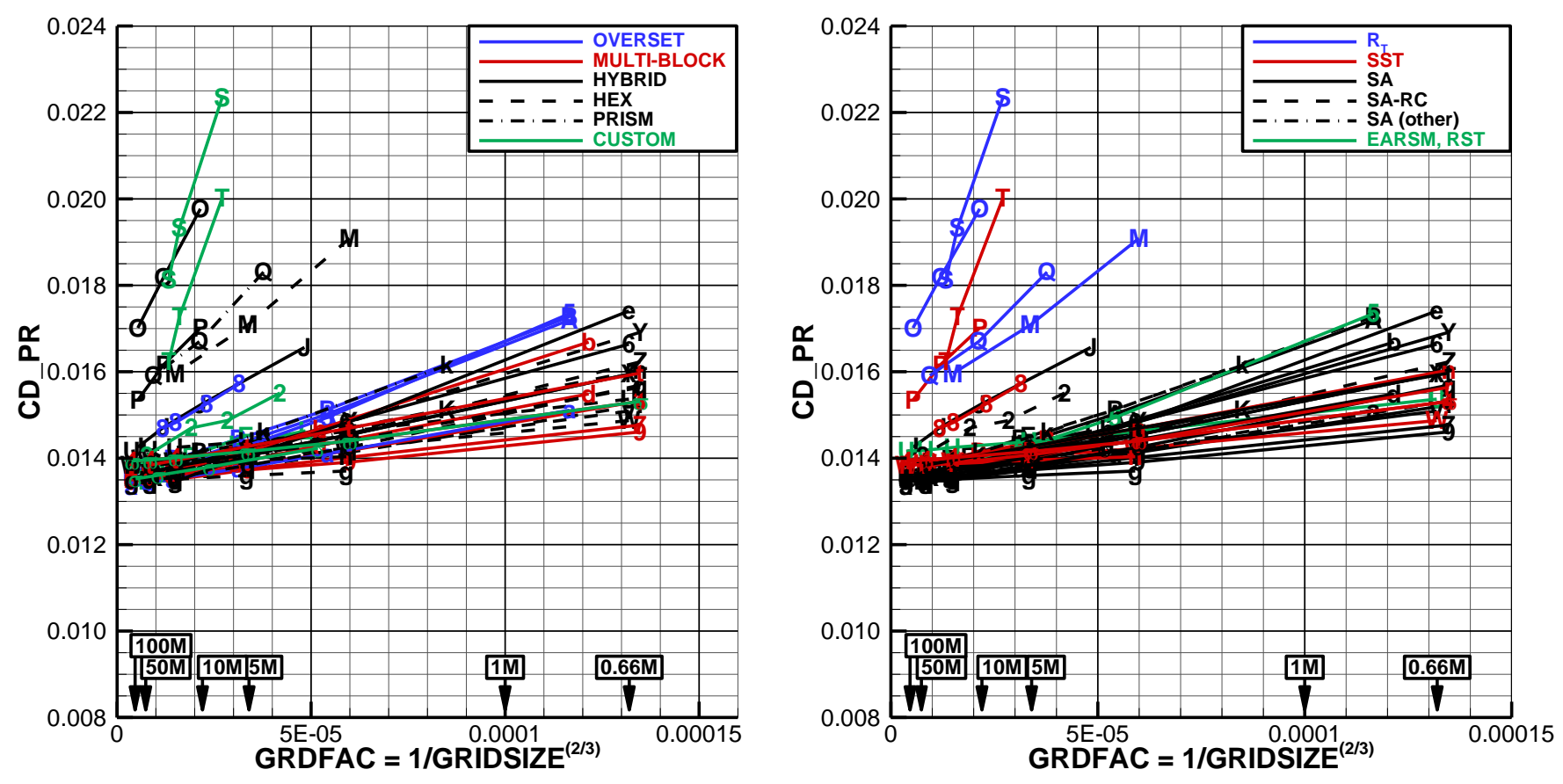

Figure 7. Case 1 Pressure Drag by Grid Type and Turbulence Model
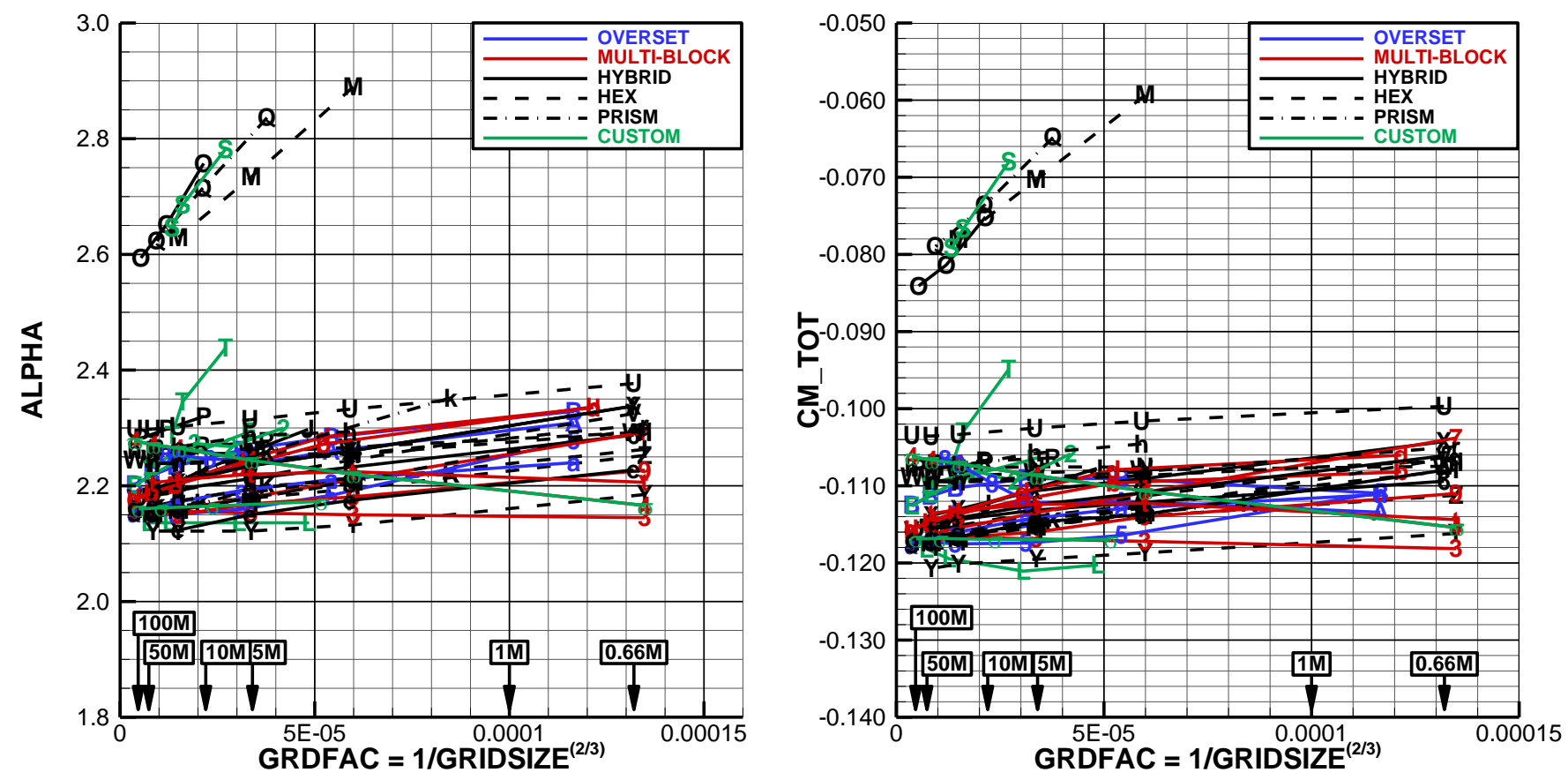

Figure 8. Case 1 Alpha and Pitching Moment by Grid Type

American Institute of Aeronautics and Astronautics 


\section{Wind Tunnel Results shown for Reference Only}

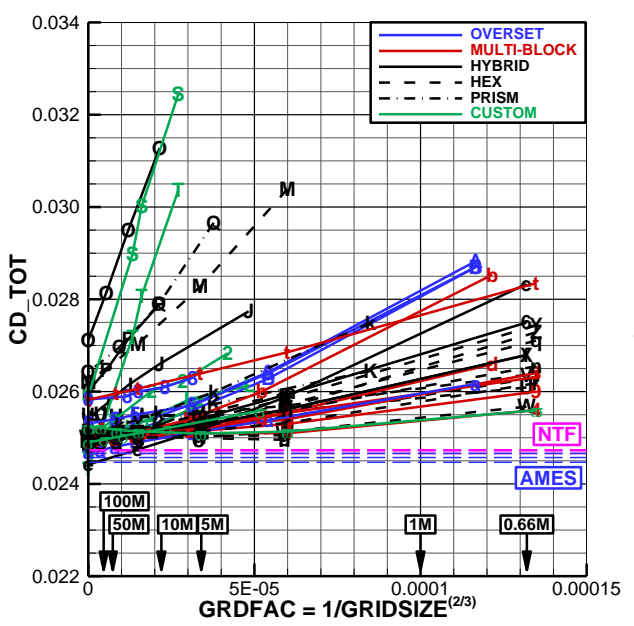

a) CD_TOT: All Grids

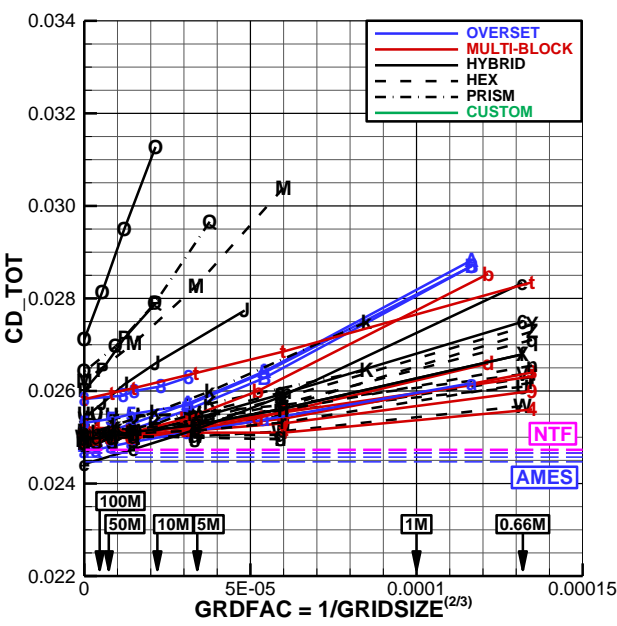

b) CD_TOT: Common Grids Only

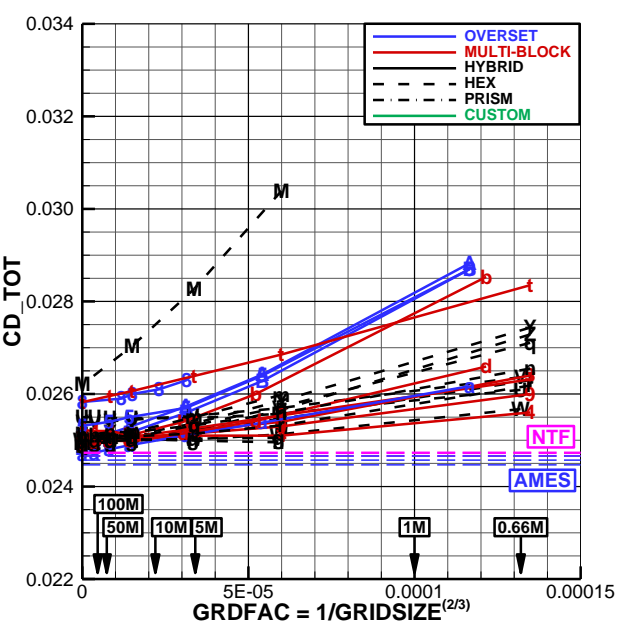

c) CD_TOT: Hex Grids Only

Figure 9. Case 1 Total Drag Richardson Extrapolation with Wind Tunnel Data

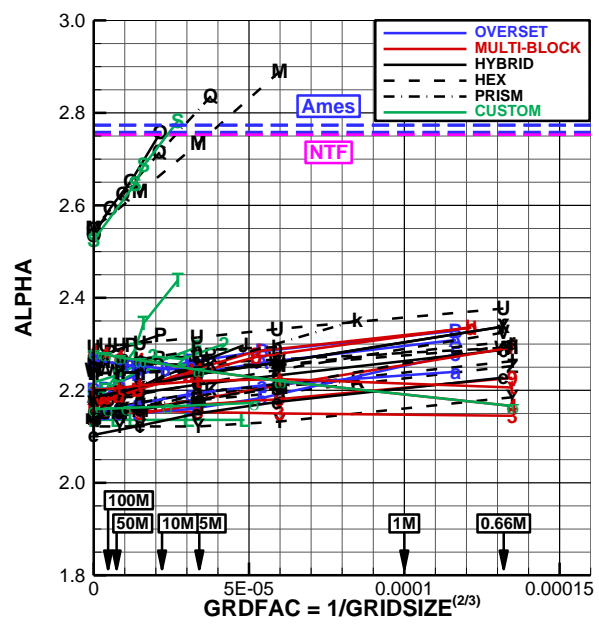

a) ALPHA: All Grids

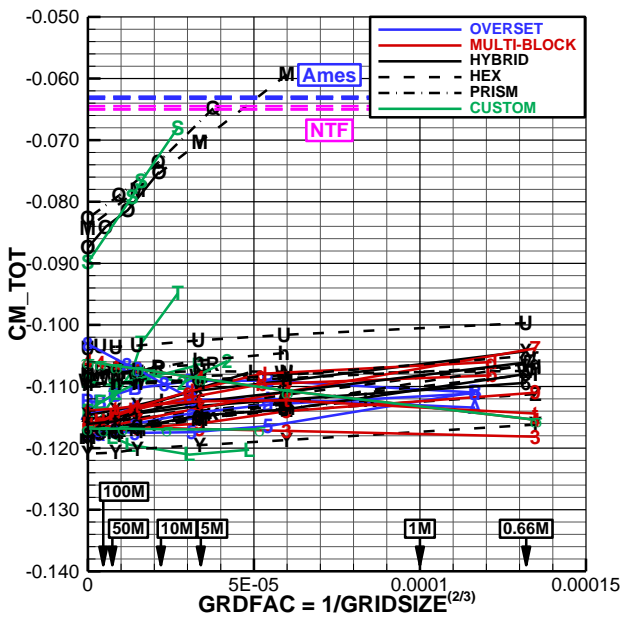

b) CM_TOT: All Grids

Figure 10. Case 1 ALPHA and CM_TOT Richardson Extrapolation with Wind Tunnel Data

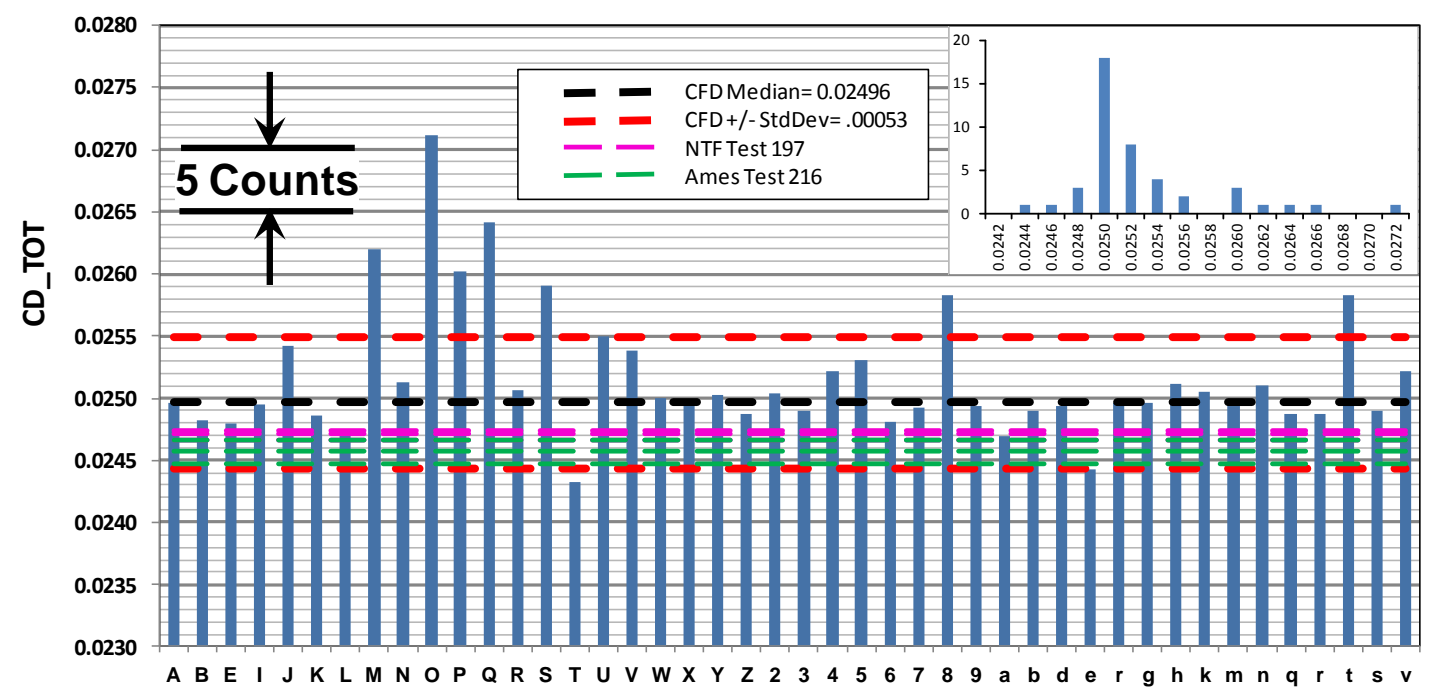

Figure 11. Case 1 Total Drag Continuum Extrapolation 21

American Institute of Aeronautics and Astronautics 

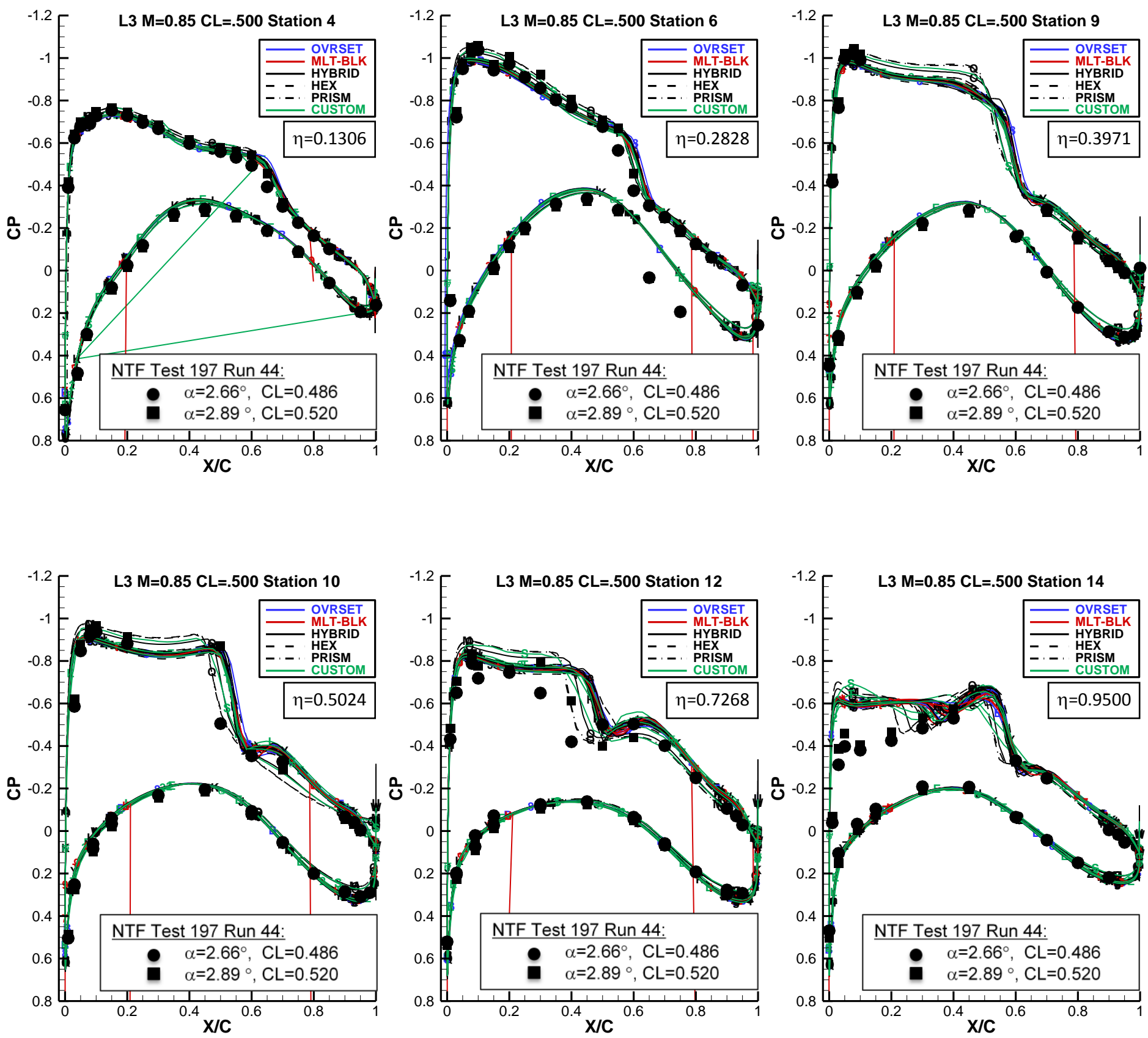

Figure 12. Case 1 Medium Grid Spanwise Variation in Wing Pressure Coefficient 

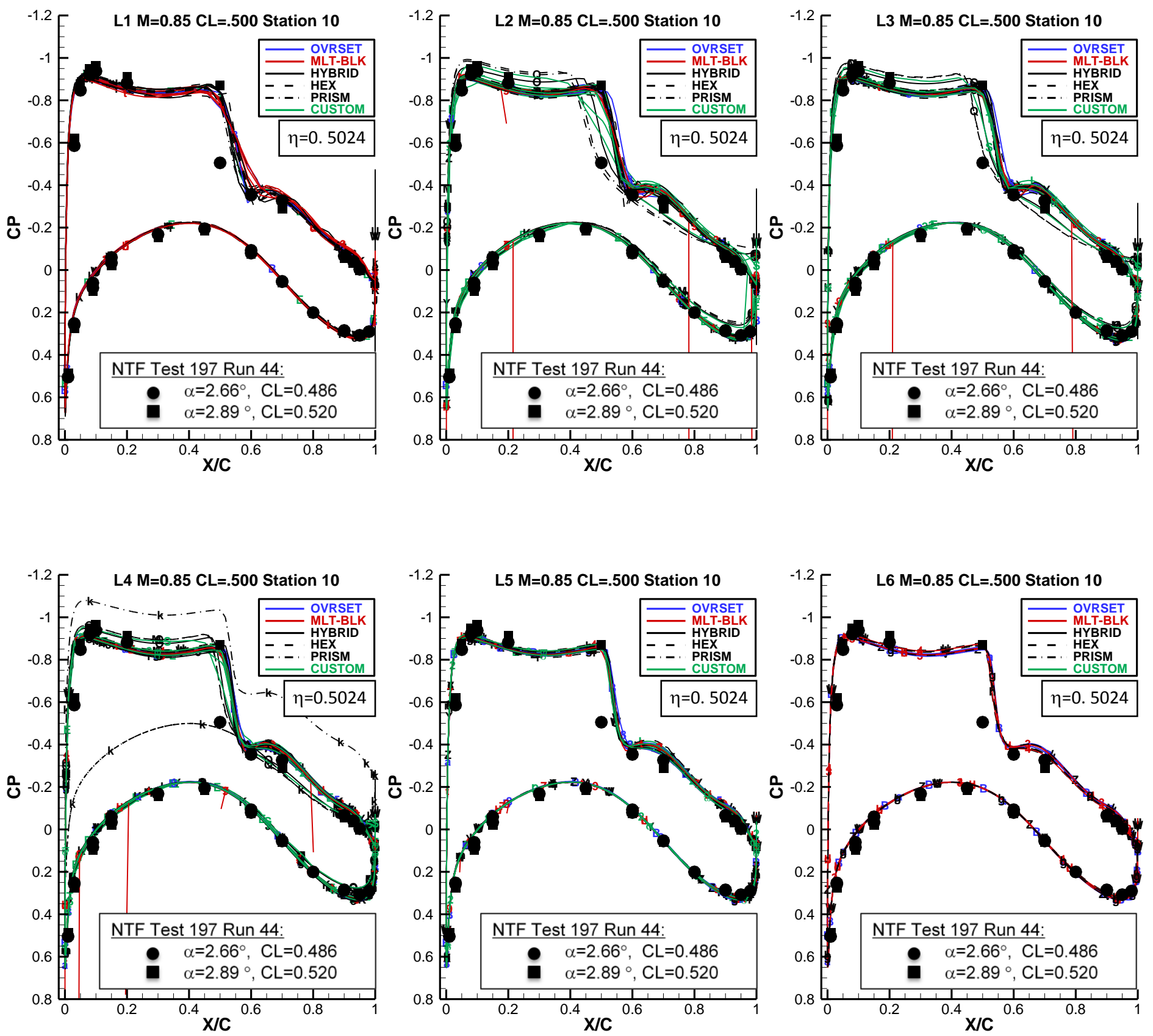

Figure 13. Case 1 Grid Refinement Trends for Wing Pressure Coefficient at Station 10 


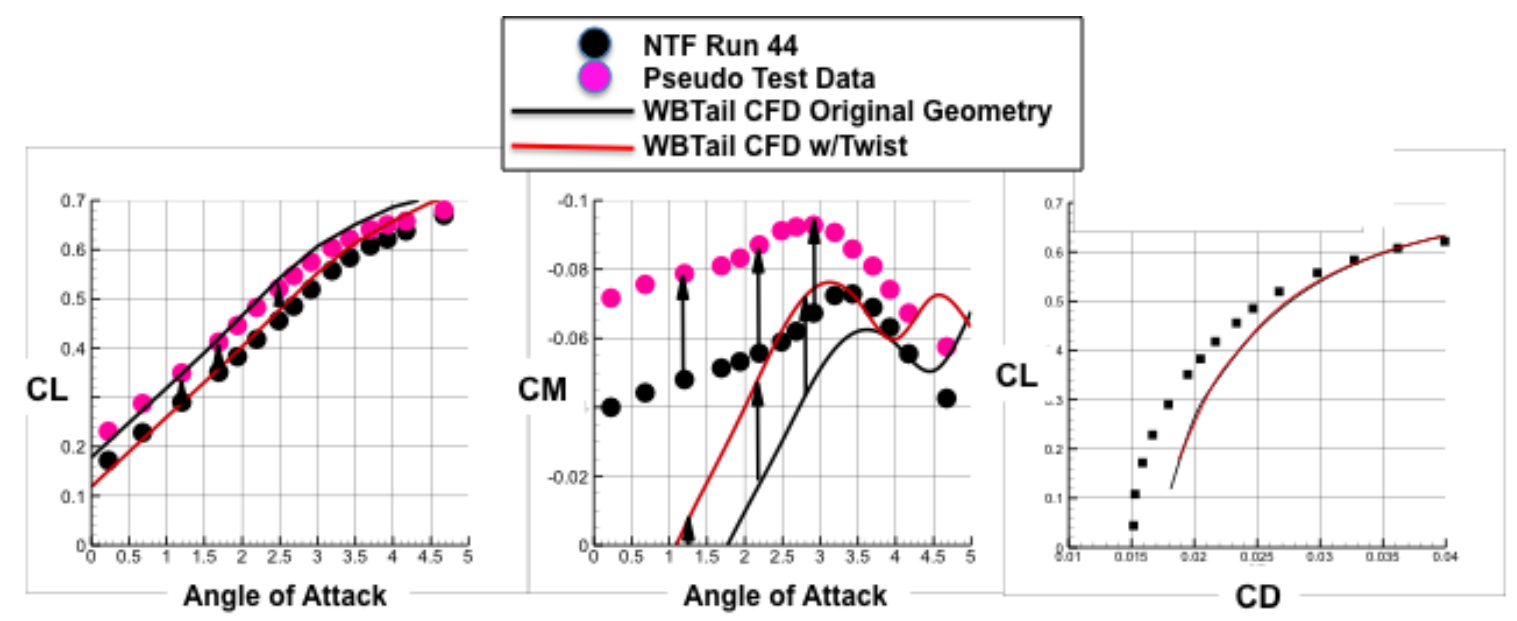

Figure 14. "Pseudo" Test Data

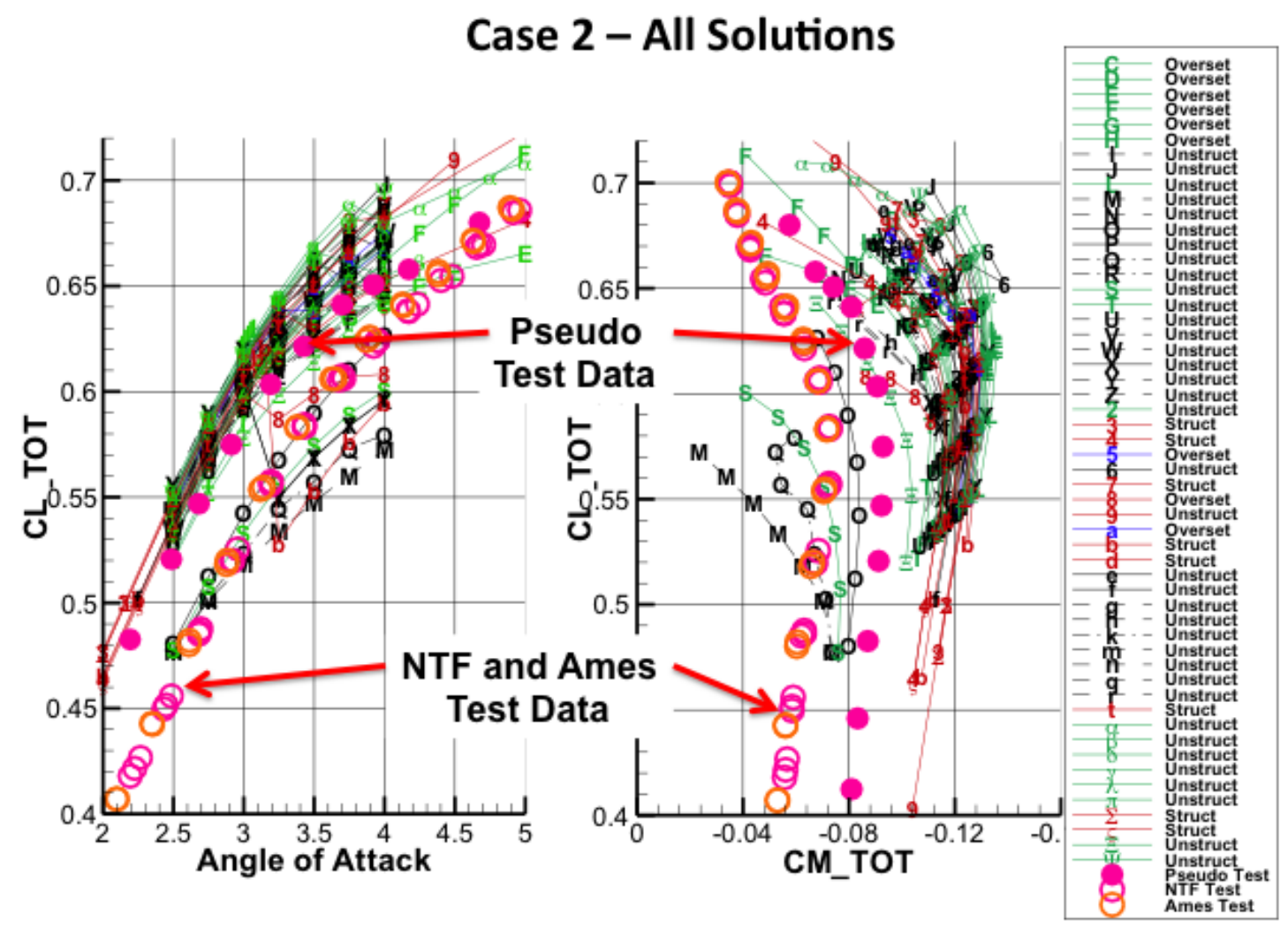

Figure 15. Lift and Pitching Moment for All Solutions 


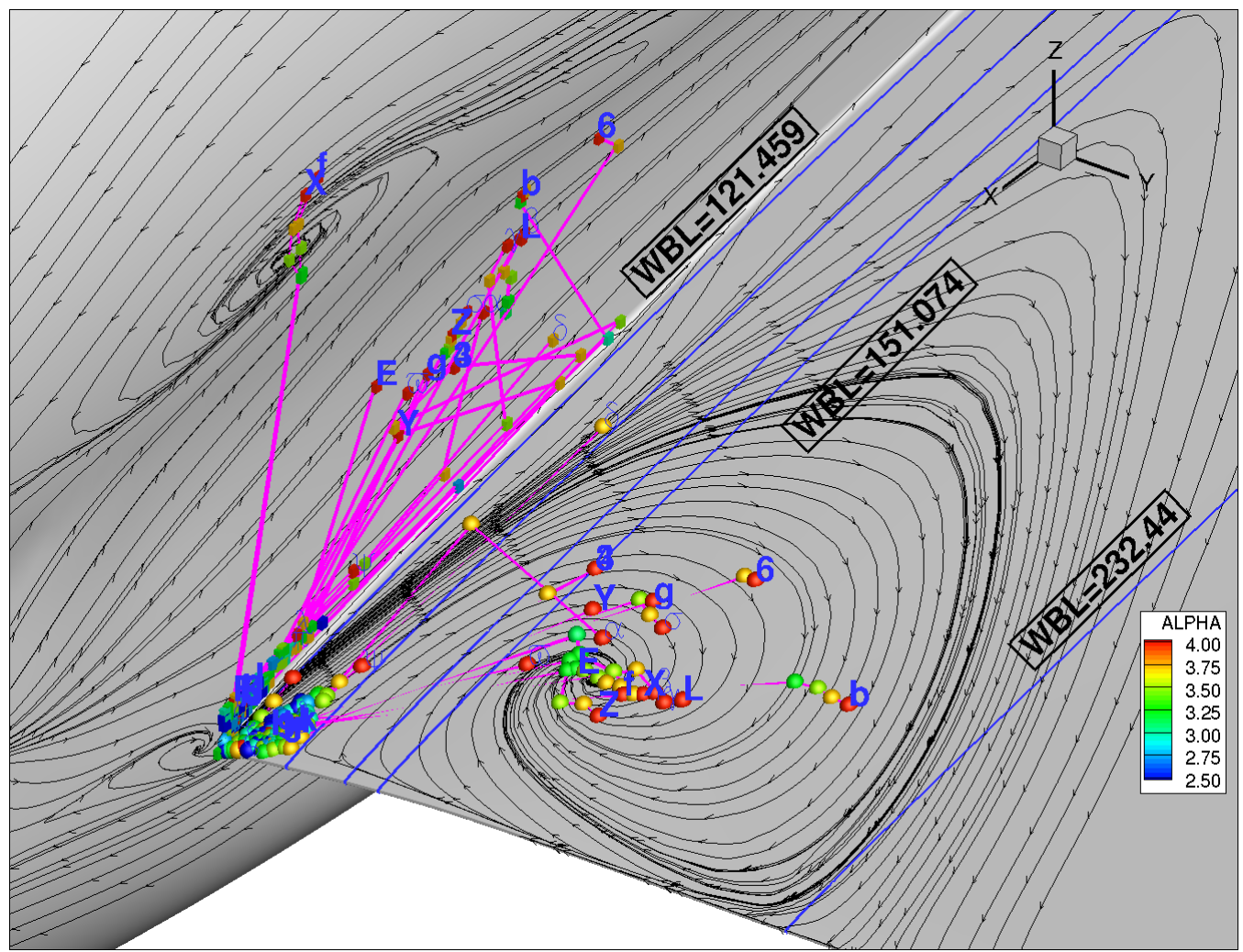

Figure 16. Wing Root Trailing Edge Separation Bubble.

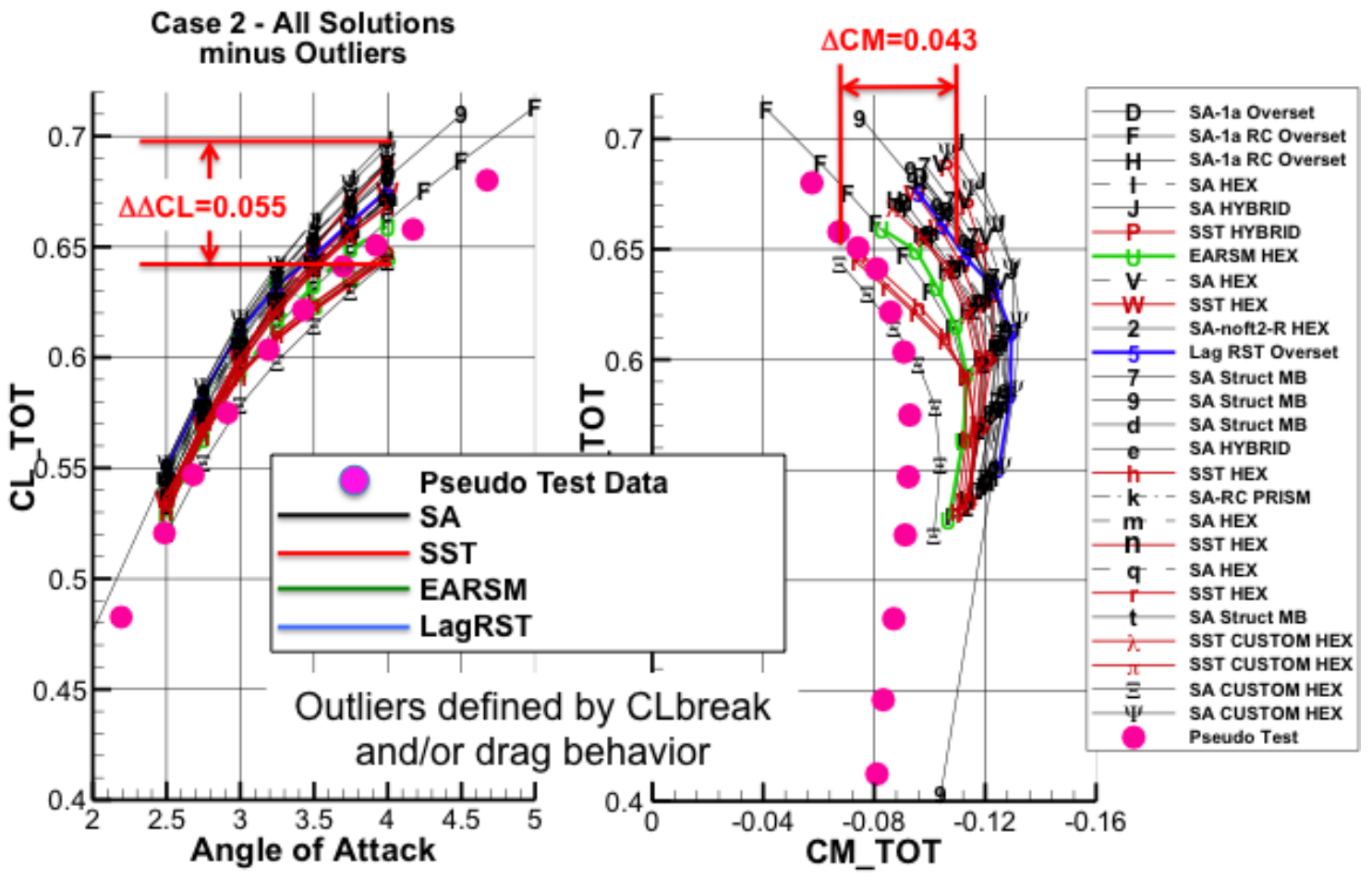

Figure 17. Lift and Pitching Moment for Solutions Minus the Outliers

American Institute of Aeronautics and Astronautics 


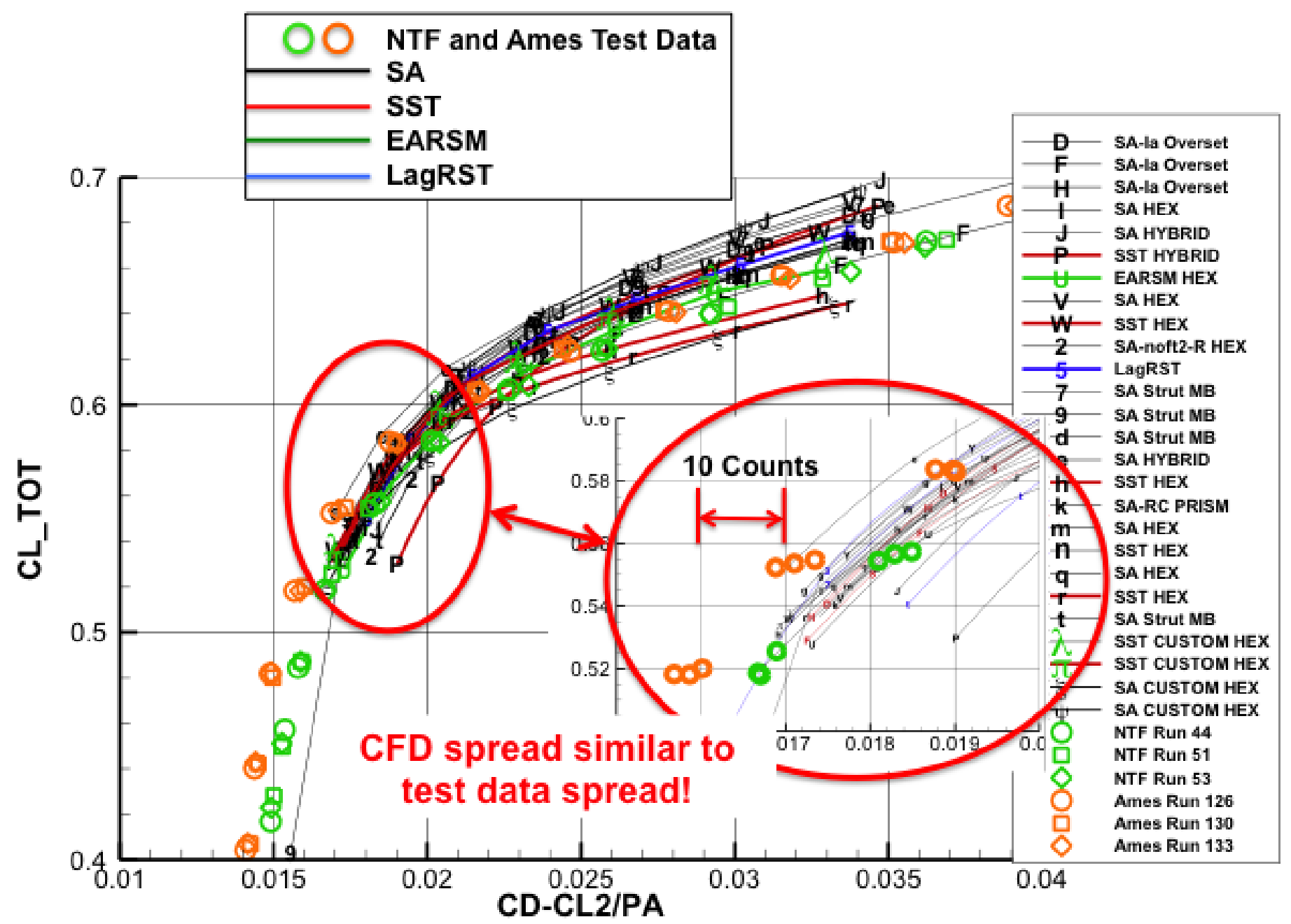

Figure 18. Idealized Drag for Solutions Without the Outliers 

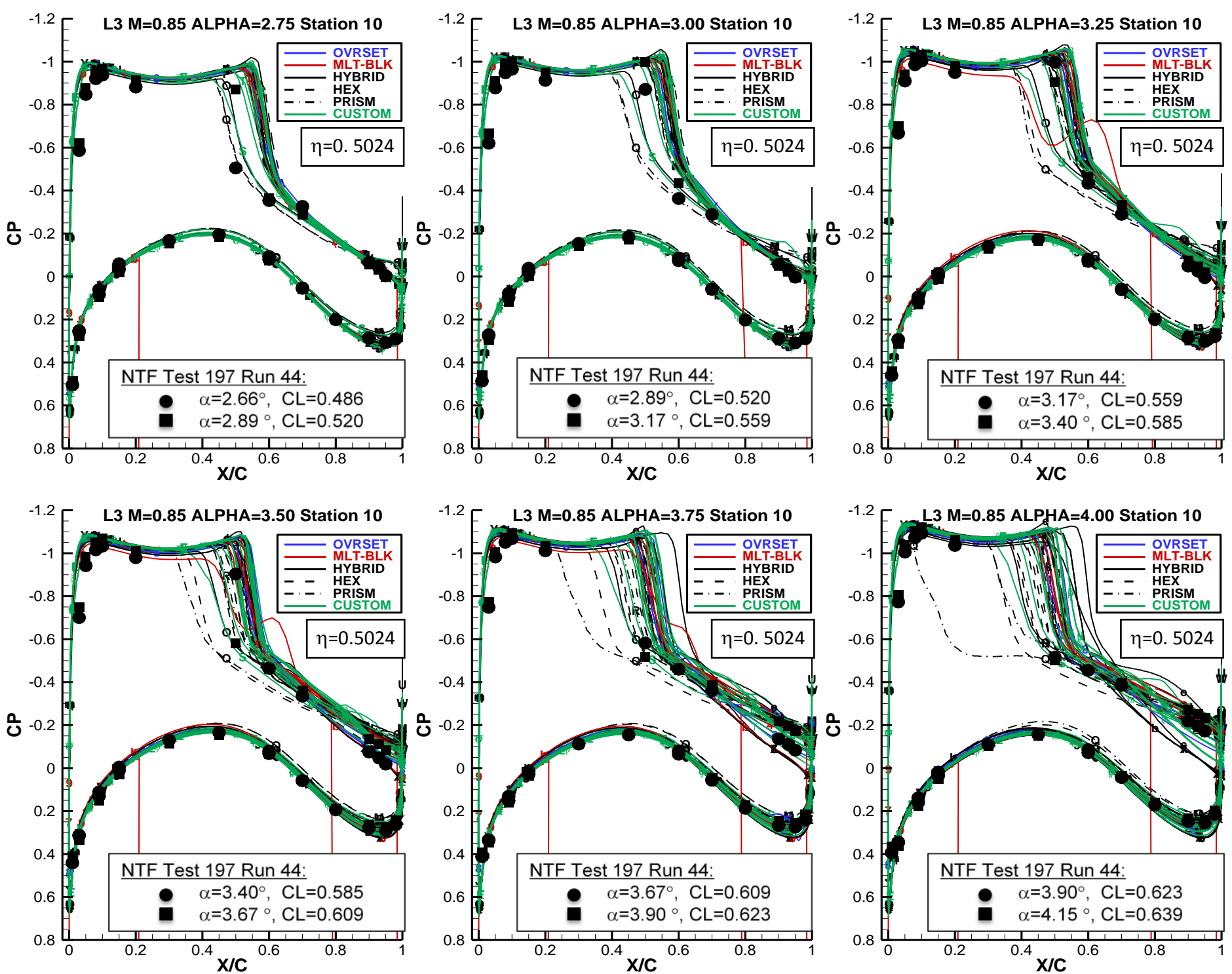

Figure 19. Case 2 Buffet Study Trends for Wing Pressure Coefficient at Station 10
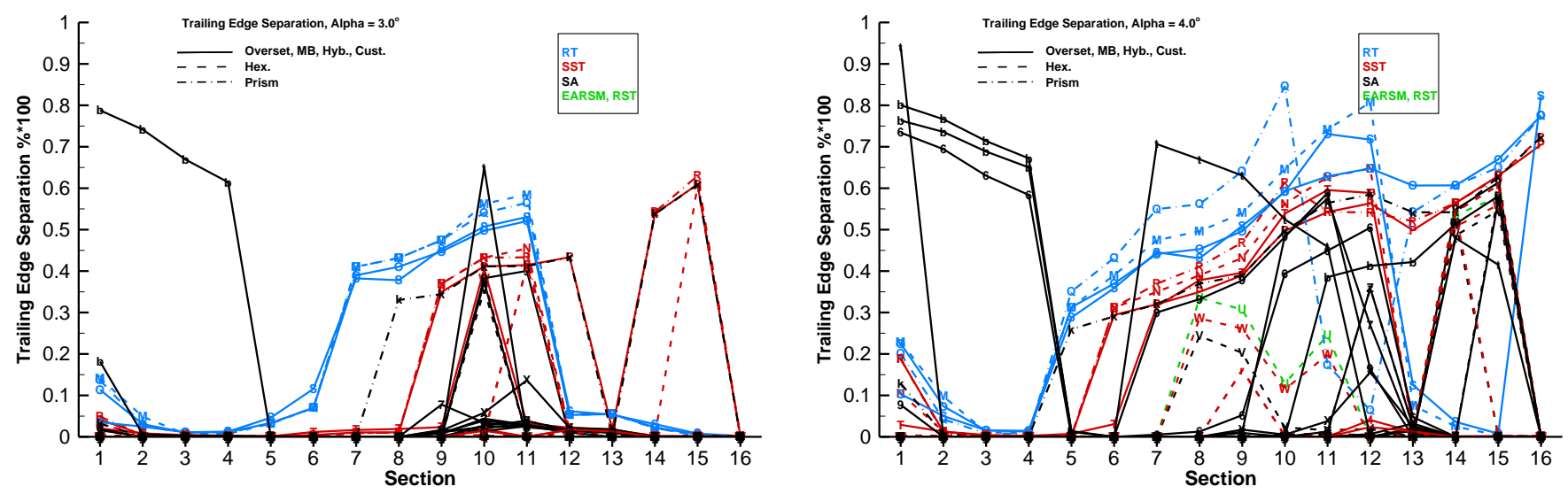

Figure 20. Trailing Edge Separation at 3.0 ${ }^{\circ}$ and 4.0 ${ }^{\circ}$ Angle-of-Attack 


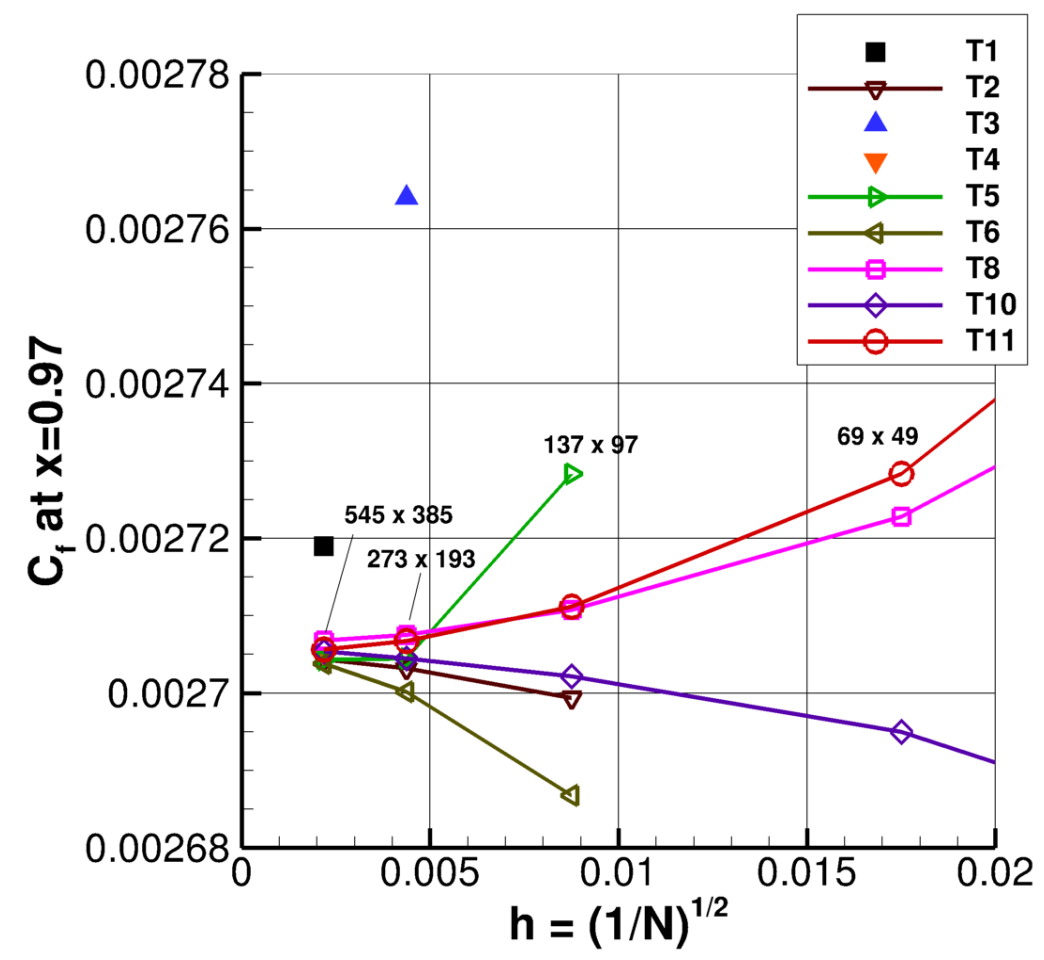

Figure 21. Grid study of flat plate skin friction coefficient using SA.

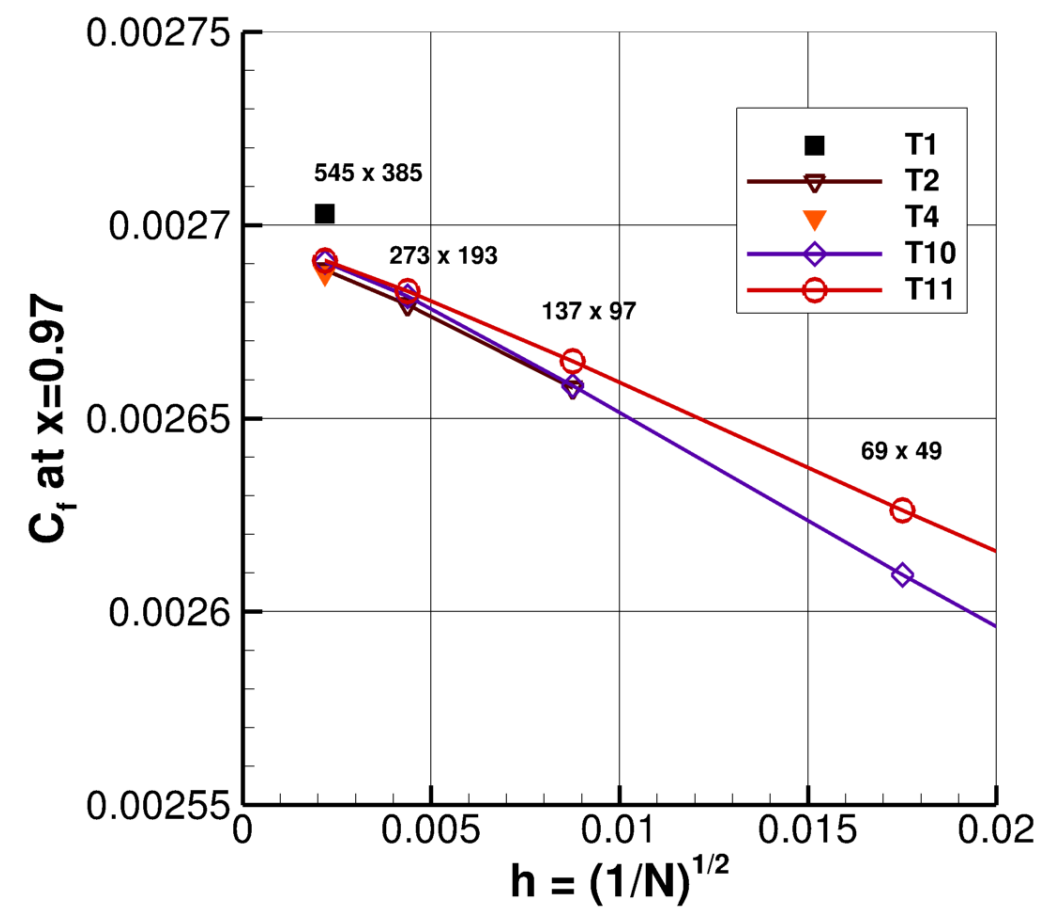

Figure 22. Grid study of flat plate skin friction coefficient using SST. 


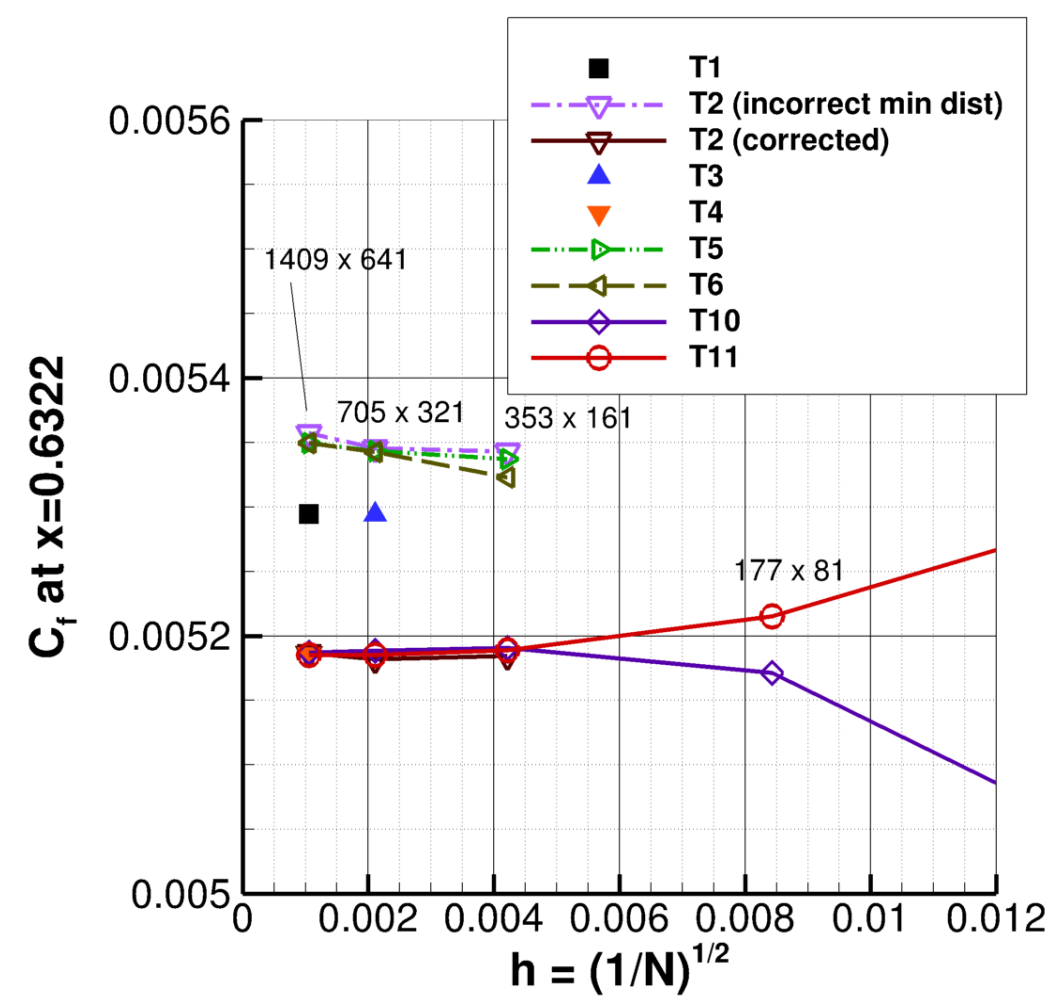

Figure 23. Grid study of bump skin friction coefficient using SA.

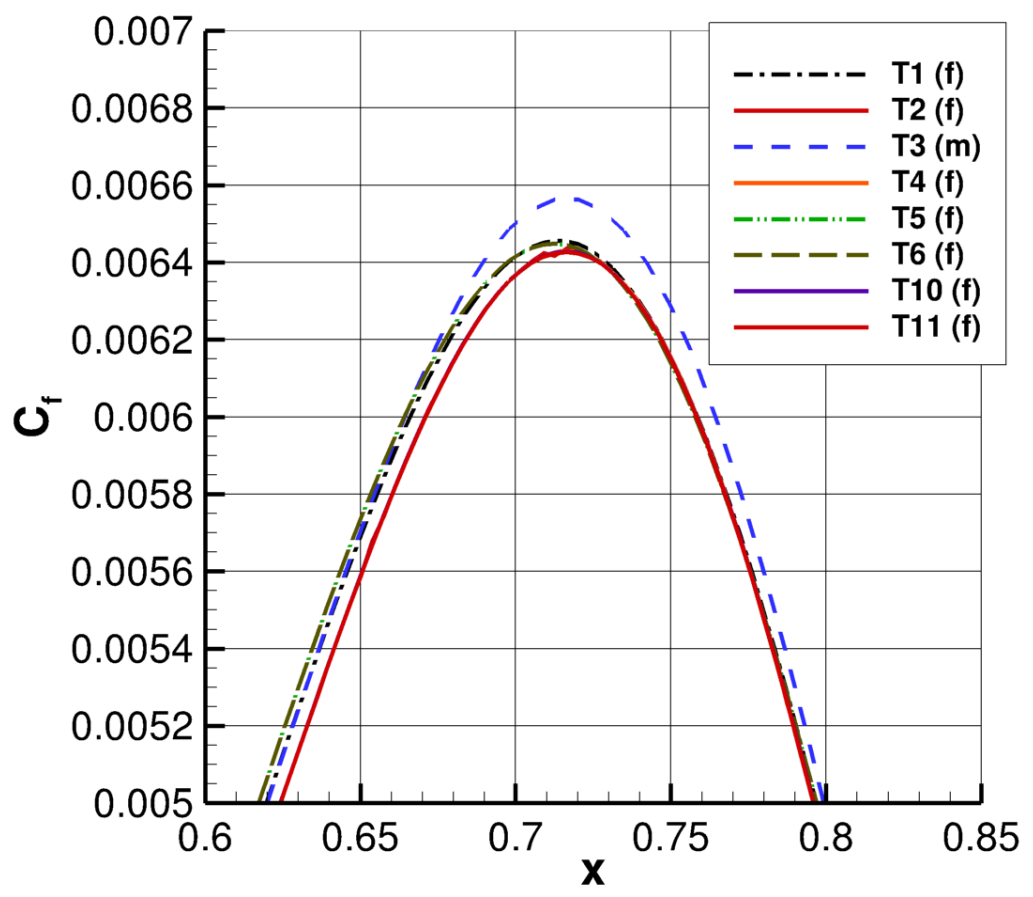

Figure 24. Skin friction coefficient over bump (detail) using SA. 


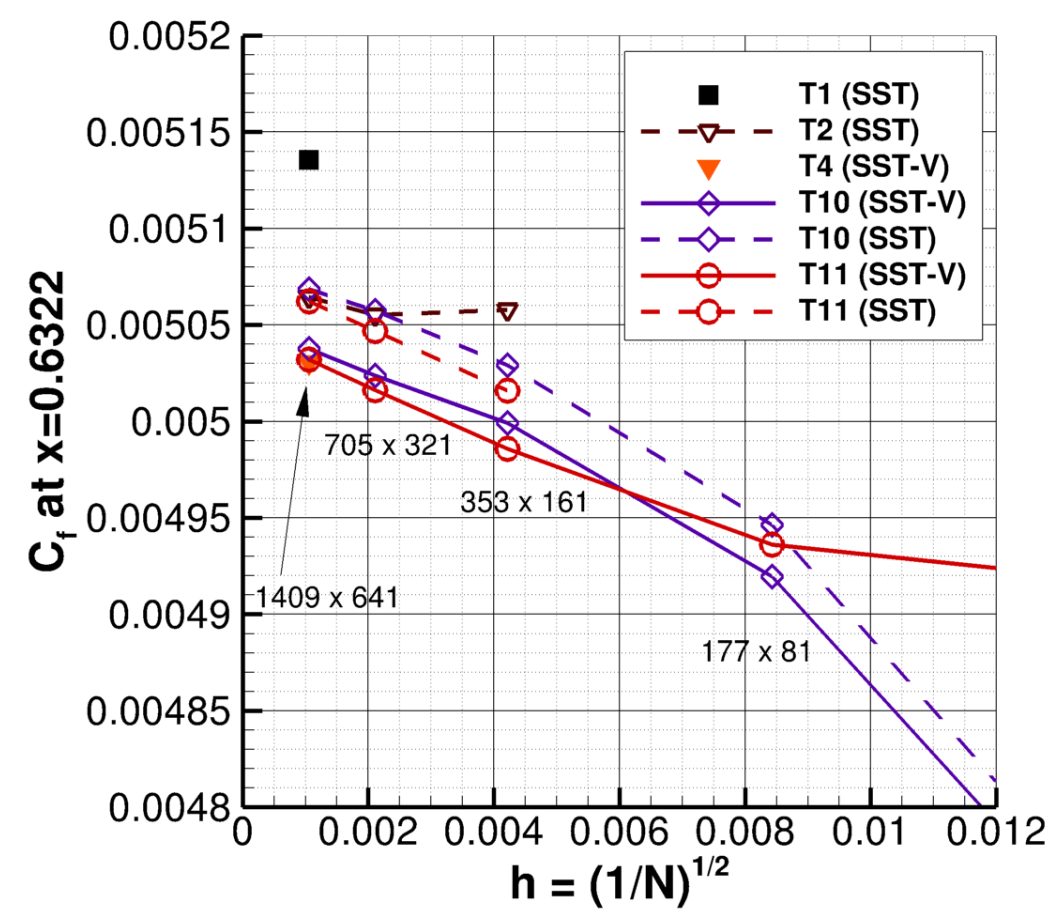

Figure 25. Grid study of bump skin friction coefficient using SST and SST-V.

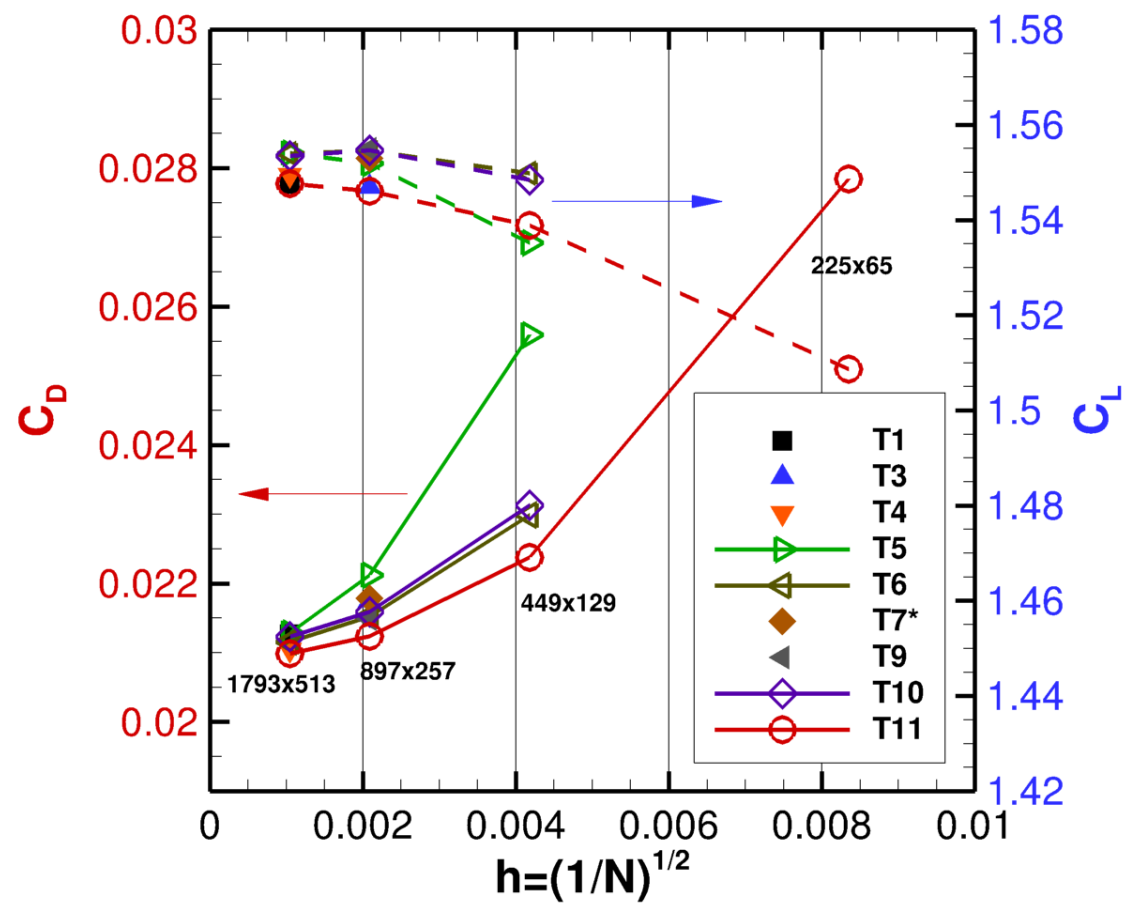

Figure 26. Grid study of NACA 0012 drag and lift coefficient at AoA=15 deg using SA. (T7 used a custom-adapted grid and is plotted with arbitrarily chosen $h$. 


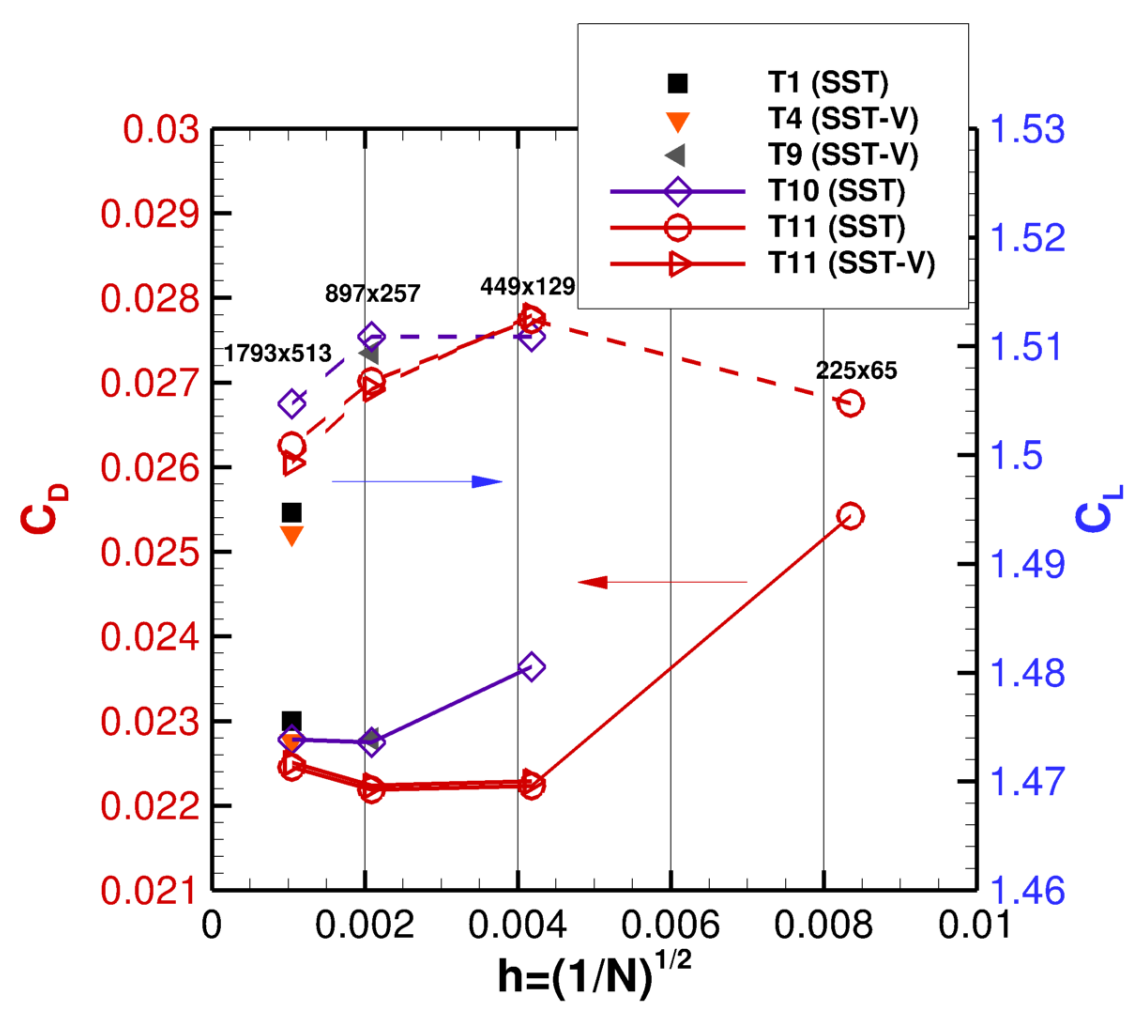

Figure 27. Grid study of NACA 0012 drag and lift coefficient at AoA=15 deg using SST and SST-V. 